Estudios Constitucionales, Año 15, No 2, 2017, pp. 83-122

ISSN 07180105

Centro de Estudios Constitucionales de Chile Universidad de Talca

"Referéndums contemporáneos: deliberación y problemas de su ejercicio en diversos contextos constitucionales"

Isaac de Paz González - Diego Isaac Amador Magaña

\title{
REFERÉNDUMS CONTEMPORÁNEOS: DELIBERACIÓN Y PROBLEMAS DE SU EJERCICIO EN DIVERSOS CONTEXTOS CONSTITUCIONALES*
}

\section{CONTEMPORARY REFERENDUMS: DELIBERATION AND EXERCISE PROBLEMS IN DIVERSE CONSTITUTIONAL CONTEXTS}

\author{
ISAAC DE PAZ GONZÁLEZ ${ }^{* *}$ \\ Universidad Autónoma de Baja California \\ isaac.depaz@uabc.edu.mx \\ Diego IsaAc Amador Magaña*** \\ Universidad Autónoma de Baja California
}

RESUMEN: Después del ejercicio de Reino Unido, en junio de 2017 y el de Cataluña en octubre de 2017, los referéndums son leit motiv para el estudio constitucional y de la ciencia politica contemporánea. Para entender el resultado y su eficacia en un marco constitucional es necesario conocer su procedimiento y teleología dentro de cada marco político y jurídico. Además, es necesario realizar un estudio de las cuestiones político-sociales y económicas que se ponen en juego con el resultado. Tomando en consideración dos formas de Estado heterogéneas, el presente trabajo analiza casos concretos de referéndums que atañen a la esfera pública de España, Reino Unido, California y los procedimientos de consulta popular en México. Los marcos estatales son distintos: Estado autonómico (España), dos Federales (México y Estados Unidos) y una Monarquia constitucional que tiene un modelo heterogéneo de organización territorial (Reino Unido). El objetivo es mostrar algunas coincidencias del referéndum como mecanismo deliberativo y algunas divergencias y problemas en la implementación del resultado. Asi, el trabajo advierte que, si bien es cierto es un mecanismo saludable para la participación social, también conlleva riesgos en su ejercicio cuando no se edifica sobre bases deliberativas y con objetivos constitucionales.

\footnotetext{
* Trabajo recibido el 25 de abril de 2017 y aprobado el 4 de octubre de 2017.

** Profesor-Investigador de la Facultad de Derecho de la Universidad Autónoma de Baja California, Campus Tijuana. Doctor en Derechos Fundamentales y Libertades Públicas por la Universidad de CastillaLa Mancha, España. Miembro del Sistema Nacional de Investigadores (México) y de The Society of Legal Scholars (Reino Unido).

*** Estudiante de la Maestría en Ciencias Jurídicas (PNPC) de la Facultad de Derecho, Campus Tijuana, de la Universidad Autónoma de Baja California.

Este artículo forma parte del proyecto PRODEP DSA/103.5/16/10204. Los autores agradecen a los evaluadores anónimos por sus comentarios y sugerencias que sin duda mejoraron el presente artículo. Todas las traducciones son nuestras.
} 
ABSTRACT: After the exercise of the United Kingdom, in June 2017 and that of Catalonia in October 2017, constitutional referendums are leitmotiv for the constitutional and contemporary political science study. To understand the result and its effectiveness in a constitutional framework it is necessary to know its procedure and teleology within each political and constitutional framework. This also implies a study of the political-social and economic issues that are at stake with the result. Taking into consideration two heterogeneous forms of state, the present work analyzes specific cases of referendums that concern the public sphere of Spain, the United Kingdom, California and the procedures of popular consultation in Mexico. The state frameworks are different: Autonomous State (Spain), two Federals (Mexico and United States) and a Constitutional Monarchy that has a heterogeneous model of territorial organization (United Kingdom). The objective is to show some coincidences of the referendum as deliberative mechanism and some divergences and problems in the implementation of the result. Thus, the work warns that while it is true is a healthy mechanism for social participation also carries risks in its exercise when it is not built on deliberative bases and with constitutional objectives.

PALABRAS CLAVE: Referéndum, Brexit, Cataluña, participación ciudadana, democracia deliberativa.

KEYWORDS: Constitutional Referendum, Brexit, Catalonia, citizen participation, deliberative democracy.

\section{INTRODUCCIÓN}

Los referéndums constitucionales tienen un uso in crescendo en diversas partes del mundo. Sin importar la tradición jurídica, tipo de Estado o forma de gobierno, dicho mecanismo de consulta democrática impulsa cambios políticos y suscita interpretaciones constitucionales de la mayor importancia local y global. Piénsese, por ejemplo, en el impacto financiero que tuvo el resultado del Brexit en países tan distintos como México y Japón: al día siguiente de aquel 23 de junio de 2017 las bolsas del mundo experimentaron una inestabilidad inusitada. ${ }^{1}$ Es por ello que el análisis del referéndum cristaliza el estado actual del sistema político, constitucional e implican temas de fondo de las tensiones de la democracia, la representación política, los derechos humanos y el objetivo de las sociedades a corto y mediano plazo. Por otra parte, los referéndums plantean la idea de una verdadera participación ciudadana dentro de una democracia, mediante consultas de los ciudadanos en asuntos que les conciernen, aunque en diversos contextos la deliberación y el debate público no es suficiente para ponderar las consecuencias políticas, económicas y jurídicas que el resultado tendría.

\footnotetext{
1 El portal mexicano, Arístegui Noticias (2017) informó el 24 de junio que "Después de conocer el resultado del referéndum en Reino Unido, el tipo de cambio saltó a un nuevo máximo de 19.55 pesos por dólar. Dicho movimiento implica una depreciación de 7.25 por ciento, la más grande desde la quiebra del banco estadounidense Lehman Brothers, en octubre de 2008 [...] Esta caida de la moneda mexicana se acerca a las mayores devaluaciones ocurridas en la historia reciente".
} 
Antes de comparar los referéndums en este trabajo, recordemos que la tradición política occidental ha edificado sus bases en la forma de Estado como definición y operación de todas las instituciones de una sociedad. Aunque no es el punto central del presente trabajo, es necesario señalar que los enfoques actuales, tanto en el Estado unitario como en del Estado federal, sugieren siempre la coordinación de las decisiones entre centro y periferia (órganos regionales) ${ }^{2}$ y que esta distinción ha influido para tomar decisiones en diversos referéndums. ${ }^{3}$ En los casos que estudiaremos, las vicisitudes del contexto local empañan la vista global del referéndum como mecanismo que está inmerso dentro de una determinada forma de Estado, de gobierno y de tradición política particular.

Dentro del contexto anteriormente esbozado, el presente trabajo tiene por objeto: a) analizar cuál es la relación entre referéndums y democracia en el sentido local y global; b) contextualizar las diferencias de los referéndums que han tenido más difusión en la esfera pública mundial ${ }^{4}$ (el Brexit, el proceso de Catalunya, el referéndum de Escocia y, tangencialmente, el de California) para reconocer las cualidades positivas y deliberativas de cada uno; c) determinar cuál es el futuro de este mecanismo de participación ciudadana en la construcción de la democracia en sociedades que exigen mejorar el acceso de los ciudadanos en la toma de decisiones del gobierno y, por último, d) analizar las consultas populares que se han intentado en el sistema constitucional de México para determinar si este modelo de participación ciudadana encaja dentro de alguna tipología comparable con las de otros contextos constitucionales.

Bajo la guía metodológica del referéndum que toca cuestiones constitucionales, el trabajo se divide en cuatro apartados. En el I se analiza el marco conceptual del referéndum como mecanismo de democracia y participación. En el II y III se estudian las vicisitudes de referéndums constitucionales en un Estado autonómico (España) y una monarquía (Reino Unido) y dos Estados federales (México, y el caso de California en Estados Unidos). Se sostiene que, en la mayoría de los casos, el resultado puede desencadenar una decisión no necesariamente positiva para las democracias y los derechos de las minorías. En el apartado IV se hace énfasis

\footnotetext{
2 Serna de la Garza (2011).

3 En el diseño de la Assembly Preparation Act, en noviembre de 2004 tres regiones votaron en contra de una asamblea regional electa por sufragio directo (MARCOU, 2011).

4 Entre 2017 y 2017, se han presentado otros procesos deliberativos importantes como el de Italia el 4 de diciembre de 2017, para modificar las reglas constitucionales en torno a la composición del Senado; otro es el de Turquía del 17 de abril de 2017, para el cambio de un sistema parlamentario a un sistema presidencialista.
} 
en que se trata de propuestas con mucha atención política pero escasa deliberación pública, con más afanes ideológicos que propuestas objetivas de progreso nacional o comunitario. Bajo el marco descrito anteriormente, en la parte final del trabajo se subrayan los efectos positivos de los referéndums en los problemas constitucionales que arroja su ejercicio.

\section{El REFERÉNDUM: DEMOCRACIA Y PARTICIPACIÓN DE LOS CIUDADANOS}

Hablar de democracia participativa es hablar de un diálogo permanente entre los representantes y los representados: pueblo y gobierno. Está claro que la democracia electoral es sólo una forma y no es sustancia. La democracia representa un proceso y un sistema de vida coherente entre medios y fines del Estado. Ante la desconfianza democrática en los partidos políticos 5 , la sociedad ha decidido, paulatinamente, abrir canales para reivindicar su capacidad de decisión y el poder que ha conferido a sus representantes. En parte, esta nueva demanda social proviene del fracaso de la representación política a través de los partidos y otros actores gubernamentales ${ }^{6}$ como entidades únicas para proteger los bienes e instituciones públicas. Así, la sociedad quiere tomar decisiones debido a la crisis de representación de los parlamentos y los partidos políticos. Se puede afirmar sin lugar a dudas que el telón del fondo de los referéndums enmarca los debates de la democracia directa o representativa que enunciaron Rousseau y Montesquieu, respectivamente. ${ }^{7}$ Por otro lado, es importante recordar la advertencia de Serafín Ortiz Ramírez, quien afirma que el referéndum es patrimonio de los pueblos

\footnotetext{
5 En México sobra literatura al respecto, por citar sólo algunos ejemplos recientes: CASANOVA Álvarez, (2013); Corona ARmenta, (coord.), (2014); sobre la corrupción en distintos países existen estudios con datos concreto sobre la influencia de los grupos de negocios en las actividades políticas. Así, YADAV (2011); sobre la corrupción de los recursos públicos en material electoral véase MendiLow, (2012). Sobre el incremento de la desconfianza en Estados Unidos y la falta de consenso véase, Hetherington (2015).

${ }^{6}$ Con la frase de Ortega y Gasset "Lo que nos pasa es que no sabemos lo que nos pasa”, Pedro Vega habla sobre la confusión contemporánea de la legitimidad política. De Vega no sólo analiza la crisis de la representación, sino que cuestiona el fracaso comunista frente al -no menos- estrepitoso fracaso liberal de la legitimidad política (pese a los intentos y justificaciones ofrecidas por Friedman, Hayeck y Fukuyama). Y es que la representación tiene fallas de origen desde su planteamiento en la teoría política moderna (de origen francés) sobre la soberanía nacional que formuló Siéyes frente a la soberanía popular de Rousseau. Cfr. DE VeGA GARCía (1996).

7 De los Santos Olivo (2010), pp. 481-483.
} 
cultos entrenados en las lides democráticas y en las escuelas de la buena política; no puede practicarse en pueblos que no tienen estas características. ${ }^{8}$

En general, no existe un concepto homogéneo de referéndum, pues data desde la antigua Roma y se consolida en la Edad Media. ${ }^{9}$ De lo que se advierte en los recientes ejercicios locales, nacionales y supranacionales podemos afirmar que se trata de un mecanismo de participación ciudadana para ratificar de propuestas o leyes concretas, para realizar cambios constitucionales (en torno a las relaciones internas de los órganos de gobierno y la organización del Estado), económicos o de política pública.

Por otro lado, los referéndums han sido aceptados en la mayoría de cartas constitucionales para reconocer el derecho de participación directa en torno a decisiones políticas y jurídicas más importantes en la agenda pública. Se pueden clasificar en varios tipos ${ }^{10}$ : supranacionales (previstos por los tratados internacionales y acuerdos regionales ${ }^{11}$ ), constitucionales (cuyas materias y alcances están fijados en la constitución), legales (que pueden abarcar temas de gobierno local y regional) y consultivos (que pueden estar previstos en leyes constitucionales o inferiores sobre distintas materia o alcances). Por sus resultados pueden ser vinculantes o meramente orientadores. Y por las autoridades que lo proponen pueden ser top down, o impulsados desde abajo por la población (bottom up). ${ }^{12}$ Asimismo, otros hallazgos demuestran que el presidencialismo incentiva los referéndums para aminorar las tensiones con los partidos políticos. ${ }^{13}$

La práctica contemporánea del referéndum abarca diversos ángulos y geografías constitucionales. Ya no es posible encasillar la figura del referéndum como categoría excluyente de una forma de gobierno o tipo de Estado, pues esa clasificación ha quedado rebasada por la práctica del mismo. En el ámbito internacional y

8 Citado por De los Santos Olivo (2010), p. 500.

9 En este sentido, Oliver Araujo (1986); y Bartolli (1965).

10 Diversos autores coinciden en esta clasificación en la que también se incluyen cuestiones territoriales y de tipo moral. En este sentido, con una perspectiva global véase Butler y RANNEY (1994).

11 Los que se han celebrado en el contexto regional europeo. Participaron diez Estados miembros y se rechazó la Constitución en 2005. Estos acuerdos son los más avanzados, pues las disposiciones respectivas tratan de crear un marco común con reglas claras de participación y vinculación. Véase Council of Europe (2005), Referendums: towards good practices in Europe). Doc. 10498, report of the Political Affairs Committe. Disponible en http://assembly.coe.int/nw/xml/XRef/Xref-XML2HTML-en.asp?fileid=17329\&lang=EN.

12 Esta clasificación es aludida por Welp (2010), p. 40.

$13 \mathrm{Al}$ menos en Latinoamérica así se han conseguido resolver algunas tensiones de corto y mediano plazo. BREUER (2009), pp. 46-47. 
nacional han surgido referéndums sobre la reforma constitucional para reducir el mandato presidencial a cinco años en Francia ${ }^{14}$, remuneración de los jueces en Irlanda $(2011)^{15}$, el control económico y geopolítico del gas en Bolivia ${ }^{16}$, el destino del gasto público en Suiza ${ }^{17}$. De un estudio sobre su conceptualización constitucional en América, Soto Barrientos señala que en varios países la participación del ciudadano se contempla a manera de consulta popular, revocación de mandado y para la creación de provincias (como Colombia, Guatemala, Perú, Costa Rica, Venezuela, Argentina, Brasil, Ecuador, Panamá, Bolivia), sólo México no lo contempla ${ }^{18}$, aunque sí contempla la consulta popular, que analizaremos en la parte final de este artículo. Como podemos ver, el uso del mecanismo no se limita a un sistema político o representativo en particular, por lo que en este trabajo nos limitamos a estudiar tipos del orden constitucional.

Para conocer el marco conceptual del referéndum es fundamental partir sobre una definición. Stephen Tierney señala que el referéndum está inmerso en la teoría contemporánea de la democracia y que "es casi una suposición intuitiva que los referéndums representan un modelo ideal democrático; que le da directamente a la voz determinante del pueblo, que captura perfectamente la colectividad popular, la soberanía popular y la equidad politica de todos los ciudadanos ${ }^{19}$ ". Los temas del referéndum tienen relaciones -básicamente-con cuatro procesos constitucionales: la fundación de nuevos Estados, la reforma de la Constitución, el establecimiento de submodelos de autonomía (España e Inglaterra) y la transferencia de poderes soberanos a las instituciones internacionales ${ }^{20}$. Aunque hay modelos muy particulares ${ }^{21}$ como el

\footnotetext{
14 Vázquez Alfaro (2001), pp. 305-315.

15 https://www.electionsireland.org/results/referendum/refdetail.cfm?ref=201129R.

16 ARrarás (2005), pp. 161-172.

17 LARs P., Feld (2003), pp. 2703-2724.

18 Soто (2013), pp. 317-346.

19 Tierney (2014), p. 19.

20 Con referencias sobre los últimos 30 años, Tierney menciona estas cifras de proliferación del mecanismo en varios países: en Reino Unido sobre los efectos devolutivos a Wales (2011); en Montenegro (2006), en Herzegovina (1992) en Timor del Este, Sudán del Sur, Europa del Este y otros lugares. Ibid., pp.1, 7. Un estudio histórico sobre los referéndums en Brasil, Chile, Europa occidental también puede observarse en Butler, David y Ranney, (1994).

${ }^{21}$ Los modelos que permitieron la aprobación de la producción legal y el consumo de cannabis en los Estados de California, Maine, Massachusetts y Nevada; o el de Suiza que prohibió la construcción de minaretes, representa una decisión con tintes sociológicos y concernientes a libertad de expresión y creencias que no es común en otros contextos. Sobre el tema suizo véase ANTONSICH, Marco, (2010), pp. 57-62.
} 
referéndum colombiano de finales de 2017, que representa la dificultad deliberativa cuando se trata de una decisión sobre una etapa traumática y las condiciones para la paz en una sociedad posconflicto. En Bolivia, también destaca que el mecanismo fue el ingrediente político dominante para la consolidación de la Constitución ${ }^{22}$.

Como se advierte, el panorama de los referéndums es amplio. Por ello, la tipología que propone Tierney se limita a los temas constitucionales y distingue dos categorías: uno que sirve u opera como instrumento de enmienda constitucional, junto con mecanismos parlamentarios y con las estructuras constitucionales existentes en un país; y el otro referéndum constitucional funciona como mecanismo de creación de nuevos Estados o nuevas Constituciones ${ }^{23}$. Por nuestra parte, advertimos que la tipología es acertada para casos de nuevas Constituciones (recordemos los procesos constituyentes de Ecuador en 2009 y Bolivia en 2007), aunque harían falta distinguir otros referéndums americanos que tienen que ver con modelos que se refieren al tema del libre desarrollo de la personalidad, como la propuesta 64 de California (que fue eco de los referéndums en Colorado y Washington para el uso recreativo del cannabis sativa que se habían ejercido en 2012). ${ }^{24}$

Por otro lado, y a pesar de que el referéndum intenta reconstruir una decisión societaria, su ejercicio (los tipos de estructuras, los procesos y los efectos -vinculantes o no- de los resultados) presentan cualidades heterogéneas y no definitivas. Tampoco hay consenso en las reglas de operación ${ }^{25}$ y sus alcances ${ }^{26}$. Se trata de un mecanismo decisorio con una tipología amplia. En Europa, los procesos recientes han servido para proponer una secesión, separación y modificación de las relaciones entre Estados (como son los casos de Escocia, el Brexit, Cataluña, o el caso de Italia). También hay esquemas como el referéndum de Bolivia (para extender el mandato

\footnotetext{
$22 \mathrm{Al}$ fortalecer la participación ciudadana el Comité Electoral de Bolivia dijo "Y fue éste el punto de divergencia de fondo sobre la Nueva Constitución. En tanto los liberales y opositores al proyecto de constitución intentaban sostener el decimonónico principio de igualdad formal, quienes elaboraron el proyecto de constitución comprendieron cabalmente, sin ningún dogma de desigualdad, que no se puede tratar de la misma forma cosas distintas, menos aún sujetos sociales". Corte Nacional Electoral. Resultados Finales. Referéndum Constituyente. Disponible en https://www.vicepresidencia.gob.bo/IMG/pdf/referendum_constituyente.pdf.

23 Tierney (2014), p. 11.

24 Diversos Estados como Arizona, Florida, Idaho, Michigan, Missouri, etc., ya la han legalizado. Véase Marijuana on Ballot (2017). Disponible en https://ballotpedia.org/Marijuana_on_the_ballot.

$25 \mathrm{Al}$ respecto véase Reidy, SUITER, (2015), pp. 159-169.

26 En algunos casos concretos las reglas sí son claras; en otros no. Un ejemplo del caos -parlamentario, judicial y ejecutivo- que plantea la necesidad de aclarar las reglas operativas y del resultado del referéndum es el Brexit.
} 
presidencial), bajo una etapa positiva de gobernanza para favorecer el desarrollo económico y los derechos humanos, pero con diversos riesgos de corrupción y erosión democrática ${ }^{27}$. En este contexto, es necesario reconocer que la democracia representativa ha sufrido una pérdida de credibilidad gracias a sus propios operadores. Ya sea por corrupción, por oportunismo, la falta de resultados positivos de esa representatividad está relacionada con la corrupción ${ }^{28}$, la debilidad del imperio del derecho y de la ausencia de la rendición de cuentas de los poderes políticos ${ }^{29}$.

El tipo de referéndum que se analiza en este trabajo es el constitucional, como mecanismo para fortalecer la democracia con el cual la soberanía del pueblo tiene un efecto devolutivo con los gobernados sobre cuestiones político-constitucionales que modificarán directamente la situación de los gobernados frente al Estado, o frente a la comunidad internacional. El referéndum constitucional pretende fortalecer la democracia participativa, pero no necesariamente la deliberación pública. Desde la perspectiva teórica Lawrence señala que es un mecanismo atractivo para que los individuos tomen libremente decisiones políticas mediante un debate extenso y con conocimiento de las implicaciones tanto individuales como colectivas del resultado ${ }^{30}$. Es así que la democracia deliberativa promueve las decisiones políticas racionales, bien informadas y en un ambiente libre de coerción o invectivas para que los ciudadanos cuenten con mayor disposición hacia los procesos de gobernanza ${ }^{31}$.

Otro aspecto a considerar sobre el referéndum es su función dentro de la democracia. Para una exteriorización del pensamiento colectivo se necesita de un pueblo activo. Como puente para mejorar el trecho entre representación política y decisión, surge el referéndum, ya que el sistema de votación popular es la llave por medio del cual se toman decisiones. Así, el referéndum facilita y amplía la representación política para afrontar los problemas de cada sociedad e incluir a la ciudadanía en las decisiones legislativas y ejecutivas. No obstante, tal como está diseñada, la representación política

\footnotetext{
$27 \mathrm{Al}$ respecto véase la crítica, soluciones y las vicisitudes que ofrece CÁrdenAS GraCiA (2017), pp. 81-112. Este tipo de referéndums también ayudaron a perpetrar el chavismo en Venezuela, así que no siempre tienen una intención democrática más saludable cuando se trata de mantener el poder.

28 SCHerer (2011) nos proporciona un análisis documental y fáctico que explica los entretelones de la corrupción política y policiaca en los últimos 15 años en México.

29 Y este otro problema constitucional que las cortes tienen que resolver. Por ejemplo, la ausencia de los mecanismos de control constitucional de los funcionarios del Poder Ejecutivo se debe a los defectos constitucionales para sancionar las decisiones políticas y administrativas de dicho poder.

30 LaWrence, (2015), pp. 139-148.

31 Ibíd. 139.
} 
(de elite) a través de los partidos políticos y los bloques de poder político institucionalizado, la democracia se torna una falacia. En este tenor, se necesita una actividad política por medio de mecanismos de diálogo popular para crear procesos, normas y políticas apegadas a los fines constitucionales y tomar decisiones fundamentales. Sin embargo, el concepto "pueblo" como órgano constitucional, apenas se halla en construcción. Así, los ciudadanos experimentan el protagonismo de su propia historia política ${ }^{32}$, con formulación de las decisiones legislativas que les afectarán directamente. En consecuencia, la participación se retoma para dar nuevas formas a las decisiones del poder y reivindicar el principio de justicia social.

En el caso de México, los referéndums no existen como tal. El único instrumento similar es la consulta popular, la cual brindaría una participación ciudadana sobre las decisiones de trascendencia constitucional, pero desde su creación en 2012, no se ha logrado ninguna consulta. No obstante, los grupos con intereses colectivos en común y los grupos indígenas cuentan con el derecho humano a ser consultados de los actos y decisiones del poder público que afecten sus intereses o derechos. Sin embargo, el derecho a la consulta sólo es un derecho de procedimiento que no necesariamente garantiza que la decisión final sea favorable a los intereses de los grupos protegidos ${ }^{33}$. Lo anterior toca un elemento clave de los procesos de deliberación, en los que se incluye el referéndum: el efecto vinculante o no de la decisión. Esto depende de cada texto constitucional o legal que defina las reglas de su ejercicio, y de las competencias constitucionales para ejercer la decisión, como lo fue el caso del Brexit, que, a pesar de la decisión, tuvo que ser la Suprema Corte de Inglaterra quien señalara al Parlamento como órgano ad hoc para iniciar el proceso de salida de la Unión Europea.

Los referéndums son una puerta efectiva para que la sociedad exprese su sentir en el proceso de gobernanza; son el reflejo de la heterogeneidad de la participación

\footnotetext{
$32 \mathrm{Al}$ menos estas han sido algunas experiencias en diversos Estados. Véase, por ejemplo, el "NO" a la integración con Europa en Chipre, en el año 2004, Pericleous, Chrysostomous (2009, pp. 273 y ss.). Sobre la influencia de los medios en la agenda del referéndum véase REICHTERT (2013).

33 En diversos amparos colectivos ya se ha presentado este dilema. En el caso del Pueblo Yaqui vs. Sonora el amparo otorgado optó por una solución procesal más que de fondo, vid. 1a Sala de la SCJN, Amparo en Revisión 631/2012 Sentencia aclaratoria 7 de agosto de 2013. El fallo reconoció el derecho a la consulta del pueblo Yaqui, pero la lesión de los derechos de propiedad ya se había consumado. Otro caso que presenta claroscuros es el del resultado del amparo de las Comunidades mayas vs. Monsanto (siembra de soya genéticamente modificada (Comunidades Mayas vs. Monsanto). Vid., 2a Sala SCJN, Amparos en revisión: 198/2015, 241//2015, 270/2015, 410/2015, 498/2015, 499/2015 y 500/2015. Resolución de 4 de noviembre de 2015), en la que el amparo les concedió la protección judicial para que se lleve a cabo la consulta a los pueblos afectados.
} 
con la intención de este proceso sea una forma de control permanente de los gobernados frente a la posible arbitrariedad del gobierno. El riesgo que corren, como veremos, es que también pueden favorecer la univocidad de los sectores políticos dominantes sin que exista reflexión sobre el impacto multisectorial de las decisiones y de los resultados. En consecuencia, y como se analizará en el apartado siguiente, la pluralidad y el debate público (sin que por ello deje se ser especializado), deben imperar cuando se proponen referéndums que impliquen decisiones constitucionales.

\section{LAS LECCIONES DEL EXTRANJERO: DIVERSIDAD Y ¿DEMAGOGIA?}

En este apartado se analizan casos concretos de referéndums constitucionales, su proceso y la implementación del resultado. Tres casos se refieren a los más connotados en Europa: el referéndum que dio pie al "Brexit" para que el Reino Unido abandone el mercado común, la jurisdicción de las Cortes de Estrasburgo y Luxemburgo, y el libre flujo de personas con la Unión Europea; el referéndum de la independencia de Escocia y el intento de referéndum para la independencia de Cataluña, bajo el "derecho a decidir" que los catalanes no pertenecen a España.

Para realizar esta comparación acudimos al marco normativo, el tipo de proceso y el efecto del resultado. La justificación de esta elección radica en la necesidad de analizar los fundamentos y alcances constitucionales de estos casos y su talante deliberativo. En un enfoque comparativo los casos de referéndums analizados en este trabajo tienen las siguientes cualidades de proceso y normativas:

Tabla 1. Referéndums analizados (elaboración propia)

\begin{tabular}{|l|l|l|l|}
\hline Referendum/Objeto & Marco Legal & Efectos & Procedimiento \\
\hline $\begin{array}{l}\text { Reino Unido } \\
\text { Brexit (2016). } \\
\text { Salida de la UE. }\end{array}$ & $\begin{array}{l}\text { European Union } \\
\text { Referendum Act 2015 }\end{array}$ & Vinculante & $\begin{array}{l}\text { Convocado por el } \\
\text { Parlamento y la Secretaria } \\
\text { de Estado. }\end{array}$ \\
\hline $\begin{array}{l}\text { España } \\
\text { (Cataluña, 2017). } \\
\text { Independencia. }\end{array}$ & $\begin{array}{l}\text { Constitución } \\
\text { Artículo 92 }\end{array}$ & Vinculante & $\begin{array}{l}\text { Convocado por el rey a } \\
\text { petición del Presidente. } \\
\text { Sancionado por el } \\
\text { Congreso. }\end{array}$ \\
\hline $\begin{array}{l}\text { Escocia (2014). } \\
\text { Independencia }\end{array}$ & $\begin{array}{l}\text { The Scottish } \\
\text { Independence } \\
\text { Referendum Act }\end{array}$ & Vinculante & $\begin{array}{l}\text { Ordenado por el } \\
\text { Parlamento de Escocia. }\end{array}$ \\
\hline $\begin{array}{l}\text { California (2016). } \\
\text { Uso de Cannabis }\end{array}$ & $\begin{array}{l}\text { Constitución Estatal } \\
\text { Artículo II, sección 9 }\end{array}$ & Vinculante & $\begin{array}{l}\text { Convoca la Secretaria de } \\
\text { Estado con requisitos } \\
\text { electorales. }\end{array}$ \\
\hline $\begin{array}{l}\text { Consulta popular } \\
\text { México (2014). Varios. }\end{array}$ & $\begin{array}{l}\text { Constitución; Artículo } \\
35\end{array}$ & $\begin{array}{l}\text { Vinculante si } \\
\text { participa 40\% } \\
\text { de electores }\end{array}$ & $\begin{array}{l}\text { Convoca poder } \\
\text { Legislativo/Ejecutivo. } \\
\text { Revisa/desecha SCJN. }\end{array}$ \\
\hline
\end{tabular}

Coinciden los puntos constitucionales que abordan; difieren en el procedimiento y convocatoria: ex profeso para el Brexit y Escocia, y a la par de las 
elecciones federales en el caso de California. Salvo en el caso de México, que ni es referéndum ni consulta, los demás son vinculantes y tienen reglas claras. El caso catalán se apartó de toda regla constitucional y legal, fue un acto político. A continuación, analizaremos cada uno de los casos concretos.

\section{A. Brexit}

El resultado del referéndum para salir de la Unión Europea fue un shock global. Lo que comenzó como una campaña negativa hacia Europa por el partido conservador de Inglaterra y UKIP (Partido de la Independencia de Inglaterra), terminó por hacer temblar la economía mundial. El resultado ha generado un análisis amplio sobre de las políticas económicas y los retos constitucionales para la Constitución de Inglaterra y su relación con los poderes públicos nacionales y regionales ${ }^{34}$. Destaca, a decir de Hauer, que en el Reino Unido sólo dos referéndums constitucionales se habían llevado a cabo. El primero en 1975 para la entrada a la Comunidad Económica Europea y el electoral de 201135. La decisión sometida a consideración del pueblo rebasó las expectativas democráticas, pues la Corte del Reino Unido ha tenido que intervenir sobre la prerrogativa constitucional ${ }^{36}$.

Para determinar que una decisión constitucional no puede someterse a la opinión popular, debido a su complejidad histórica y al futuro inmediato de toda una nación, recordemos que Reino Unido se vuelve parte de la comunidad europea en 1973. Posteriormente se genera el Tratado de Lisboa (2004), cuyo artículo 50 es la puerta de salida de los países partes de la Unión Europea "de acuerdo con sus reglas constitucionales".

El 23 de junio de 2017, con apoyo de la Ley de Referéndums de 2015 de la Unión Europea, se lleva a cabo el referéndum con la pregunta: "Should the United Kindom remain a member of the European Union or leave the European Union?" El resultado fue a favor de salir de la Unión Europea. Las primeras implicaciones

\footnotetext{
34 Vease, por ejemplo, un análisis sobre la forma en que las instituciones de Inglaterra abordarían el tema en GORDON, (2017), pp. 409-444.

35 Auer, (2017), pp. 397-408.

36 Más adelante nos referiremos al fallo expresado por la Suprema Corte de Justicia del Reino Unido $R$ (on the application of Miller and another) (Respondents) $v$ Secretary of State for Exiting the European Union (Appellant) [2017] UKSC5, 24 de enero de 2017, en la que alude a las prerrogativas del Parlamento en una decisión de abandonar la Unión Europea.
} 
fueron económicas: depreciación de la libra esterlina ${ }^{37}$ y un futuro impredecible para la permanencia en el mercado común, con todas las incertidumbres para la agenda laboral, comercial y política que eso conlleva, afectando a ciudadanos del Reino Unido que viven o trabajan en el resto de los países europeos y viceversa.

Ahora bien, el estudio jurídico que se hace del mismo nos remite a la sentencia dictada por la High Court of Justice en fecha 3 de noviembre de 2017, en la que se estudia la decisión del Brexit desde el punto de vista de los principios constitucionales de soberanía del Parlamento y poder de prerrogativa de la Corona. En ese sentido la High Court of Justice advirtió lo establecido por el artículo 50 y resolvió el dilema de quién tiene el poder para poder accionar el artículo 50 del Tratado de Lisboa y salir de la Unión Europea. La High Court falló en favor del Parlamento y estableció que el Primer Ministro no tiene el poder para poder accionar el artículo 50 del Tratado, pues bien se trata de una decisión que debe ser tomada con base a los poderes del Parlamento ${ }^{38}$. Cabe mencionar que la sentencia fue recurrida y ha sido objeto de debate dentro de la Suprema Corte del Reino Unido, quien confirmó los argumentos de la High Court sobre las prerrogativas del Parlamento; toda vez que las normas derivadas de esos tratados se volvían normas constitucionales, la decisión le corresponde al poder parlamentario. La Suprema Corte del Reino Unido explicó en forma amplia que los poderes y atribuciones del Parlamento cuando se trata de cuestiones constitucionales y de relaciones frente a otros Estados el Primer Ministro no debe ejercer ${ }^{39}$.

En este sentido, surge la cuestión de que si el resultado del referéndum y la voluntad popular tienen un verdadero valor vinculante. EL 2 de febrero de 2017 el Parlamento votó a favor del gobierno para que comenzara a planear la salida de la Unión Europea ${ }^{40}$. Consecuentemente, el Parlamento cumplirá el mandato

\footnotetext{
37 Véanse, por ejemplo, las notas sobre la imprecedente devaluación según The Guardian "The post-Brexit pound - how sterling's fall affects you and the UK economy". Bargain-hunting tourists are flocking to the UK to exploit the plunging pound but Britons are burning money on their summer holiday in Europe. "Pound slumps to 31-year low following Brexit vote". Results from across the country suggesting the Brexit camp were on the brink of declaring a referendum victory saw sterling down 10\% against the dollar. https://www.theguardian. com/business/2017/jun/23/british-pound-given-boost-by-projected-remain-win-in-eu-referendum.

38 The Queen on the application and The Secretary of State for Exiting the European Union. CO/3809/2017 \& CO/3281/2017 (High Court of Justice Royal Court, 3 de noviembre de 2017).

$39 R$ (On the application of Miller and another) (Respondents) v Secretary of State for exiting the European Union (appellant) 2017.

40 El white paper menciona: "And that is what we are seeing today. Business isn't calling to reverse the result, but planning to make a success of it. The House of Commons has voted overwhelmingly for us to get on with it.
} 
popular para las negociaciones para que Reino Unido abandone la Unión Europa, no obstante que la mayoría de la población no votó en el referéndum; aunque el sector reaccionario criticó a la Corte Suprema por "contravenir la voluntad popular" ${ }^{41}$ y que la decisión tiene implicaciones en todos los sectores de vida laboral, turística, industrial, académica, artística y económica para el Reino Unido.

En la decisión de $R$ (Miller and Others) vs. Home State Departament, la Corte sostuvo que una ley del Parlamento está obligada a autorizar a los ministros a dar aviso de la decisión del Reino Unido de retirarse de la Unión Europea. La Corte Suprema dijo que la ley requerida para implementar el resultado del referéndum debe hacerse a través de la legislación constitucional ${ }^{42}$.

Sin embargo, un punto defectuoso del resultado del Brexit es el plan para la salida. Los que apoyaron el referéndum del Brexit nunca tuvieron un plan para implementar la salida y enfrentar las consecuencias de SI. El debate que permeó en la opinión pública fue la supuesta inmigración perniciosa, la banalización sobre el gasto del Reino Unido y la injerencia de las cortes regionales en el sistema británico. Hasta octubre de 2017, ni el Parlamento ni la Primera Ministra habían logrado establecer un plan completo ni medianamente claro de las negociaciones con los miembros de la Unión Europea e incluso se baraja la posibilidad de un segundo referéndum ${ }^{43}$.

Por otra parte, varias preguntas trascendentes sobre todas las relaciones comerciales, industriales, aduanales, de cooperación militar y seguridad (medidas antiterrorismo), quedan en el aire en la relación Reino Unido-Unión Europa. En especial aquellas relativas al futuro de la jurisdicción contenciosa de los derechos humanos ante la Corte Europea. Cabe aquí la interrogante jes el Parlamento la autoridad competente para determinar la supresión de los derechos humanos (y la

\footnotetext{
And the overwhelming majority of people - however they voted - want us to get on with it too".'Policy Paper The United Kingdom's exit from, and new partnership with, the European Union'. Disponible en https://www. gov.uk/government/publications/the-united-kingdoms-exit-from-and-new-partnership-with-the-europeanunion-white-paper/the-united-kingdoms-exit-from-and-new-partnership-with-the-european-union-2.

41 En defensa de la decisión de la Corte, Robertson (2017) dijo: "How can they, the Brexiteers angrily ask, defy the will of the people, in a democracy? Despite the fact that they would be defying the will of only 37 per cent of the people, it has to be pointed out that these objectors do not know the true meaning of democracy".

$42 \mathrm{Cfr}$. $R$ (on the application of Miller and another) (Respondents) $v$ Secretary of State for Exiting the European Union (Appellant), Press Summary, 24 de enero de 2017.

43 La Cámara de los Comunes ha publicado una lista de los asuntos más relevantes en torno al Brexit en que se expresan las preocupaciones, las influencias de los medios en la cultura democrática británica y las implicaciones del Brexit para Irlanda y Escocia. (House of Commons, 2017).
} 
respectiva jurisdicción contenciosa de la Corte Europea) adquiridos por el pueblo inglés, tras la celebración de los Tratados Internacionales que unieron a Europa? La respuesta no es sencilla, los derechos humanos no se pueden suprimir, puesto que no se trata de prerrogativas disponibles para el Parlamento ${ }^{44}$. Mediante The House of Lords, el Parlamento Británico recientemente adujo que los derechos de los británicos que viven en la Unión Europea -y de ciudadanos europeos que viven en Inglaterra- deben ser garantizados, al mencionar que: no se puede $j u$ gar a la política con sus vidas ni con su futuro ${ }^{45}$. Otra incapacidad del gobierno para ejecutar el Brexit es que durante todo 2017, los plazos, términos, debates y negociaciones de la salida del Reino Unido, no han podido concretarse.

La desinformación antes del referéndum del Brexit es un buen ejemplo del porqué cuidar el proceso deliberativo y el diálogo social de aquellas decisiones de la democracia directa. En ese caso, no hubo un consenso orientado a discutir las ideas con el cuidado que el tema merecía. No se fijó una agenda con los renglones importantes y un marco de información sobre las verdaderas consecuencias del Brexit en todos los ámbitos de la vida británica. Más bien, se le dio un tratamiento coloquial con un discurso que se inscribe en la línea del cierre político que experimentan algunas sociedades ${ }^{46}$ con tintes sino demagógicos, sí poco objetivos y

$44 \mathrm{El}$ artículo 53 de la Convención Europea de Derechos Fundamentales reconoce ciertos límites para la supresión de los derechos: "Nivel de protección. Ninguna de las disposiciones de la presente Carta podrá interpretarse como limitativa o lesiva de los derechos humanos y libertades fundamentales reconocidos, en su respectivo. Ámbito de aplicación, por el Derecho de la Unión, el Derecho internacional y los convenios internacionales de los que son parte la Unión, la Comunidad o los Estados miembros, y en particular el Convenio Europeo para la Protección de los Derechos Humanos y de las Libertades Fundamentales, así como por las constituciones de los Estados miembros".

45 Se ha discutido con pros y contras el problema del respeto a la voluntad general y la intervención del Parlamento en las negociaciones de salida entabladas por el Gobierno. La intención de la discusión parlamentaria va enfocada en identificar cada una de las áreas en que la salida del mercado común afectaría la industria, la pesca, la ganadería, la educación, el mercado laboral; áreas que requieren el mayor análisis en el que la voluntad popular debe dar cabida a la racionalidad legislativa. Véase: House of Commons, European Union (Notification of Withdrawal) Bill, vol. 641. Disponible en https://hansard. parliament.uk/Commons/2017-02-08/debates/B9545C0C-B593-43E4-A12E-2AD5D47DEFE4/ EuropeanUnion(NotificationOfWithdrawal)Bill\#division-7082.

46 Se puede afirmar que los nacionalismos combinados con la demagogia están de regreso, sin importar el grado de desarrollo y supuesto progreso de la comunidad política. Donald J. Trump como presidente de la nación más influyente a escala global (en las Naciones Unidas, en el Banco Mundial, el Fondo Monetario Internacional, en la IVY League, con bases militares por todo el mundo), es un claro ejemplo de que en una nación desarrollada la democracia no garantiza un líder con autoridad moral o política que favorezca la buena gobernanza. 
erróneos ${ }^{47}$. El ejercicio británico muestra de la ausencia de una metodología clara para modificar -mediante el referéndum- las instituciones políticas, jurídicas, sociales y que se han construido en los campos de la industria, el comercio, el flujo de personas, el mercado común y los lazos educativos, culturales, de seguridad y de cooperación militar, desde el tratado de Roma en $1957^{48}$ a la fecha, es una vuelta a los nacionalismos excluyentes.

\section{B. Caso Cataluña}

El 1 de octubre de 2017, pese a las prohibiciones constitucionales, jurisdiccionales y legales, los líderes políticos catalanes convocaron a un referéndum que se llevó a cabo en un contexto de confrontación entre votantes y fuerzas del Estado. No se pudo agotar la vía del pacto con España para lograr el proceso de independencia ${ }^{49}$. El argumento esencial que sostienen los independentistas catalanes es: el pueblo catalán es soberano y alega un derecho a decidir su vida política mediante su separación de España. ${ }^{50}$ El problema merece analizar sus antecedentes. Los intentos de la Generalitat de abrir las vías a la separación mediante el derecho a decidir ya habían sido declarados nulos mediante la sentencia 42/2014 del Tribunal Constitucional español (en adelante, TCE) que estimó inconstitucional y nulo el

47 Frases como "Let's take back control" u otra como "We want our country back", instigadas por el grupo política pro-brexit, permearon en la opinión pública inglesa para convencer al electorado de salir de la Unión Europea. Muy parecida a las frases de Donald Trump ("Make America Great Again"). En la prensa los impulsores del Brexit criticaban que el 60\% de las leyes del Parlamento se hacían en Europa, que existían interferencias con asuntos financieros del Reino Unido, también se dejó ver un recelo hacia los jueces europeos, y que la inmigración era algo descontrolado para Europa e Inglaterra. Véase "UK óbliged' to accept judgments of European courts, official document from ministers ahead of EU referendum reveals". The Telegraph. Disponible en http://www.telegraph.co.uk/news/2017/04/14/uk-obliged-judgments-of-europeancourts-official-document-from-m/.

48 Aunque Reino Unido ingresó al tratado (junto con Dinamarca e Irlanda) en 1973, para unirse al bloque económico la República Federal Alemana, Holanda, Bélgica, Francia, Italia y Luxemburgo (así desde 1973 las piezas del comercio, la fijación de tarifas aduanales y el flujo migratorio se convirtió en el antecedente del mercado común de Europa).

49 Proceso Independista Catalán, "Podemos apoyar un referéndum de independencia en Cataluña”, https:// mundo.sputniknews.com/espana/201709191063553620-espana-cataluna-independencia-siqueespot/ Consultada: 19 de septiembre de 2017.

50 Martin Scheinin sostiene por su parte que, en efecto, los catalanes pueden "no tener derecho a la secesión, pero sí tienen derecho a reclamar ese derecho". Blog IACL-AIDC, (2017): "Catalans May Not Have the Right to Unilateral Secession - But They Do Possess the Right to Present Such a Claim", disponible en https://iacl-aidc-blog.org/2017/10/09/catalans-may-not-have-the-right-to-unilateral-secession-but-they-dopossess-the-right-to-present-such-a-claim/. 
principio de "Soberanía" de la Declaración aprobada por la Resolución 5/X del Parlamento de Cataluña ${ }^{51}$. Posteriormente se anularon diversos intentos de Cataluña para lograr hacer una consulta o referéndums en favor de la independencia ${ }^{52}$. El TCE de España menciona que la declaración manifestaba como soberanía y la facultad del pueblo para decidir no se debe entender que es un derecho de autodeterminación, sino más bien como una aspiración política mediante la cual puede llegarse bajo el proceso ajustado a la legalidad constitucional; y en cuanto a la soberanía el TCE declara la nulidad de este punto, pues se contrapone con la soberanía constitucional ${ }^{53}$.

Como antesala del referéndum catalán, debemos señalar que el diseño constitucional de 1978 no instaló un federalismo, sino un modelo autonómico, el cual ha generado severos cuestionamientos ${ }^{54}$ por ser fuente de problemas y reclamos de independencia. Otra crítica proviene de López Aguilar, quien ha postulado por la idea de que el Estado Autonómico Español no está en la Constitución, sino que se ha establecido por las leyes y la jurisprudencia emitida por el Tribunal Constitucional Español, no sólo en el caso catalán ${ }^{55}$, sino en el caso del País Vasco para frenar el Plan Ibarretxe ${ }^{56}$. Hay otro aspecto importante, un referéndum no puede decidir cuestiones de separación o secesión, no se trata de un derecho a decidir, como Cataluña lo pide; pues nada tiene que ver con elegir el que ya no

51 Tribunal Constitucional de España, Sentencia 42/2014, publicada en el Boletín Oficial del Estado en 10 de abril de 2014 .

52 José María Castellá Andreu señala que "De ellas, las vías legales que se han intentado seguir hasta ahora por las instituciones catalanas para llevar a cabo la consulta del 9-N han sido: 1) la solicitud en abril de 2014 al Congreso de la delegación a la Generalitat de la competencia estatal para autorizar la convocatoria de un referéndum a la población catalana; 2) la aprobación de la Ley catalana 10/2014, de consultas populares no referendarias, en septiembre 2014; y, tras la suspensión de la misma y del decreto de convocatoria de la consulta no referendaria del 9-N (Decreto 129/2014) por parte del Tribunal Constitucional, 3) la organización de un proceso participativo, carente de todo apoyo legal, y también impugnado por el Gobierno, por tratarse de una pseudo-consulta o pseudo-referéndum y que también fue suspendido por el Alto Tribunal'. CASTELLÁ ANDREU (2014), pp. 229-240.

53 Un estudio completo de este aspecto lo presenta Ferreres Comella (2017).

54 Para el maestro Pedro de Vega (2012) la Autonomía no era un tema constitucional como criterio definidor de la vida democrática del consenso en la Constitución de 1978. Se entendía que se hablara de libertad, de la amnistía para los perseguidos por el franquismo, pero no entendía el porqué de la autonomía. Cfr. Conferencia de Pedro Vega, Instituto de Administración Pública. Ciclo de conferencias "La reforma del Estado y de la Administración española", 29 de noviembre de 2012, disponible en https://vimeo.com/56802960, fecha de consulta: 10 de marzo de 2017.

55 Aguilar (2017), pp. 273-308.

56 Se trata de la sentencia del Tribunal Constitucional Español STC 103/2008. 
se desea formar parte de un Estado. ${ }^{57}$ El riesgo de estos planteamientos a través del referéndum es que se llega a un callejón sin salida. El 10 de octubre de 2017 el presidente de Cataluña emitió un mensaje para suspender la declaración de independencia. ${ }^{58}$

Consideramos que el ejercicio catalán ha enfrentado no sólo un planteamiento erróneo sobre la democracia y la autodeterminación, y los efectos nocivos que puede tener para su economía, sino que también es una forma inadecuada de enfrentar la crisis constitucional que se vive sobre el Estado Autonómico frente al Federalismo ${ }^{59}$. De un análisis, post factum, ninguna de las justificaciones a favor de la independencia catalana fraguó en el ámbito político español ni europeo, salvo que la atención mediática global nos permite reflexionar sobre el sentido racional del referéndum frente a conceptos añejos como independencia o democracia.

De acuerdo con los datos que analiza Castellá Andreu, el argumento a favor fue que se trataba de una decisión democrática y legítima del pueblo catalán a modo, por ejemplo, se afirmó que en el derecho comparado (Brexit, Escocia o Quebec) existen experiencias positivas a favor del referéndum. Lo que no se dice es que, en Escocia y Quebec, se siguió el guion marcado por los estatutos constitucionales para organizar el referéndum. Además, no se pueden comparar estas categorías porque en tales referéndums hubo pactos políticos previos como fue el caso de Escocia. El de Quebec se sujetó estrictamente al marco constitucional sin dar cabida a la secesión unilateral del territorio ${ }^{60}$. Asimismo, en el caso de Quebec, el diálogo fue una obligación sine qua non, y si no se llegó a un acuerdo, cualquier declaración de independencia hubiese sido ilegal en el derecho interno. ${ }^{61}$ Por otra parte, también se debe reconocer que todo el mapa del asunto catalán esconde la crisis política de los partidos dominantes que puede derivar en una crisis constitucional que -dicho sea de paso- le ha restado valor al Tribunal

\footnotetext{
57 Incluso el gobierno español pudo haber activado el artículo 155 de la Constitución Española que ordena a las comunidades autónomas el cumplimiento forzoso de las medidas y acciones que dicte el interés público. 58 Ver El País (2017): "Puigdemont prolonga la tensión con una secesión en diferido". Disponible en: https://elpais.com/ccaa/2017/10/10/catalunya/1507624143_410500.html (última fecha de consulta: 12 de octubre de 2017).

59 Aguilar (2017), pp. 273-308. En el mismo sentido Cagiao y Conde (2015) subraya los vicios de origen y las grietas del modelo de Estado español.

60 Ibídem.

61 Gaudreault-Desbiens (2017), p. 153.
} 
Constitucional para abrumarlo con cuestiones políticas debido a un mal manejo de las formulas conciliatorias de los actores políticos ${ }^{62}$.

En realidad, el trasfondo del referéndum catalán es la necesaria reforma constitucional que España seguramente llevará a cabo en el mediano plazo, pues como ya se ha visto en el supuesto que llegara a realizarse la independencia catalana, las preguntas pendientes serían su poco probable membresía en la Unión Europea, el uso de la moneda y el reconocimiento internacional a través de tratados y relaciones comerciales. Finalmente, las lecciones que podemos aprender de Cataluña son las de mejorar las herramientas para crear mayor deliberación en los disensos políticos. Como lo menciona López Aguilar: "No es cierto que la democracia consista en decidir sobre cualquier cosa, de cualquier modo, en cualquier momento, con desprecio de los tiempos y los procedimientos [...] La independencia de Cataluña no debe ser decidida, ni en este caso ni en ninguno, en una fractura binaria de la sociedad catalana ${ }^{63}$ ". En este punto, podemos añadir que el debate de fondo es la peligrosidad del nacionalismo como argumento fútil para justificar privilegios económicos de una región que ha sido favorecida y que abusa del concepto de "independencia” para reclamar un mejor trato. ${ }^{64}$ Por lo demás, la única ventaja para España es que se ha abierto la puerta para una reforma constitucional del Estado Autonómico ${ }^{65}$.

\section{Escocia}

El 18 de septiembre de 2014 una mayoría en Escocia vota en referéndum por la negativa de independencia y de abandonar el Reino Unido. Se obtuvo una respuesta contundente por parte del pueblo escocés para mantener sus vínculos con Reino Unido. Si bien en la Constitución - no codificada- del Reino Unido

62 Como la de ejecutar - a manera de brazo autoritario- las decisiones que por la ausencia de consensos políticos surjan. Véase la crítica que realiza AGUILAR, Juan: "La cúpula del PP apostó entonces por dinamitar así lo que seguramente fue la penúltima oportunidad de encajar la voluntad de buena parte de la sociedad catalana de obtener un reconocimiento a su singularidad (intensidad de identidad y voluntad de autogobierno) en una España plural cuya arquitectura no puede ser ya sino un Estado federal'. Op. cit., p. 303.

63 López Aguilar, Op. cit., p. 298.

${ }^{64}$ El editorial de la revista satírica francesa Charlie Hebdo, critica no sólo el fallido referéndum sino los motivos económicos y que no existe ninguna opresión ni destino trágico del que Cataluña quiera librarse. (Charlie Hebdo, 2017).

65 Véase la nota "Rajoy activa el 155 con apoyo del PSOE y accede a reformar la Constitución", (El País, 2017). Disponible en https://politica.elpais.com/politica/2017/10/11/actualidad/1507705563_381296.html. 
no existe un derecho formal de secesión, Escocia tuvo el derecho a plantear si abandonaba el Reino Unido. Este referéndum de independencia contó con la deliberación necesaria para analizar los pros y contras de la decisión que estaban por tomar; entre esos pros y contras se determinó la cuestión económica: comercio, mercado común, moneda, directivas europeas de producción, sedes de los bancos. Los pro-independencia sostenían que se podía llegar a acuerdos sobre relaciones comerciales, ${ }^{66}$ aunque, como se vio en el caso del Brexit y Cataluña, la decisión independentista no aclara el panorama post factum, ni ofrece soluciones económicas de corto o mediano plazo. Por otro lado, este referéndum puso al descubierto la necesidad de mejorar las "convenciones constitucionales" entendidas como la reunión de personas interesadas para examinar los acuerdos constitucionales con el propósito de reformarlos ${ }^{67}$, con la intención de dar voz y participación directa -que en esta época- es una exigencia de la gente ${ }^{68}$.

Cabe resaltar, que -a diferencia de lo que sucede en Cataluña- el planteamiento de Escocia para separarse de Reino Unido es parte de un proceso devolutivo iniciado desde hace algunos años ${ }^{69}$; y que cambia de escenario totalmente ante la posible salida del Reino Unido de la Unión Europea (al accionar el artículo 50 del Tratado de Lisboa). Escocia, ante esta situación enfrentaría un panorama complejo para mantenerse en la UE, pues lo preocupante es que perderían sus derechos adquiridos dentro de la UE y el Reino Unido. Además, la seguridad hemisférica podría sufrir cambios, ya que los defensores de la independencia escocesa pretendían cerrar la base militar submarina que se encuentra en Escocia ${ }^{70}$, cuestión que podría fracturar la relación con la Organización del Tratado del Atlántico Norte. Ahora bien, quedan otros temas pendientes, y preguntas para decidir si: ¿Se puede renunciar al Convenio Europeo de Derechos Humanos?, ¿es aceptable

66 PAGE (2017) núm. 37.

67 Davies, (2015), pp. 277-297. El autor cita tres casos importantes de las convenciones constitucionales en Australia en 1998 para definir si se mantenía una monarquía constitucional; el caso de Irlanda para permanecer o no dentro del Reino Unido en 1973 y de Irlanda en 2011 para que los ciudadanos decidieran los cambios de varias de sus instituciones constitucionales (edad para votar, número de legisladores, etc.).

68 Davies afirma que "Clearly, however, in an era of seemingly ever increasing political disenchantment, there is an acceptance amongst the political classes that the people need to be more directly involved in constitutional discussions; referenda are a more common tool now than they have been in the past". Ibid., p. 295.

69 Desde 1999, a través de normas constitucionales, el Parlamento británico inició un proceso para devolver competencias a Wales y Escocia, tomando en cuenta la diferenciación política, regional y como sus rasgos nacionales en el sentido cultural. TRENCH (2010), pp. 31 y ss.

70 Piris (2017), núm. 37, pp. 101-134. 
que exista regresividad de los derechos políticos, humanos y económicos? ¿Cuáles son los límites de estas modificaciones constitucionales de los Estados respecto de sus ciudadanos?

Las preguntas planteadas no admiten una respuesta que no implique cuestionar el verdadero sentido de progreso de una democracia madura y coherente con el deber de proteger a las minorías de las mayorías, pues diversos estudios demuestran cómo los derechos de las minorías son erosionados como resultado de los referéndums ${ }^{71}$. Así, los referéndums tocan profundas fibras constitucionales sobre márgenes muy tenues entre Derecho, Política, Economía y las relaciones internacionales. En una época de conexiones globales, ninguna decisión por muy local que parezca, está aislada del escenario internacional. Consideramos un contrasentido hablar de cierres y nacionalismos cuando desde hace varias décadas se predicaba una lucha por la democracia global y el universalismo de los derechos humanos.

Existe ahora una posibilidad de hablar -en el caso de Cataluña y Escocia- de la obligación para Reino Unido y España de mantenerse territorialmente íntegros, es decir, conservar su totalidad territorial, ¿se podría entonces hablar de utilizar a las Cortes Constitucionales para evitar dichos mecanismos separatistas? El Parlamento Europeo se había mantenido en silencio ante estas posturas, pero, a tres días del referéndum expresaron su preocupación e interés en que España se mantenga unida y con respeto a su Estado constitucional ${ }^{72}$. No han establecido dentro de los tratados alguna manifestación formal, y bajo esa tesitura -si no hay nada expreso, que prohíba a las partes a mantener su territorio intacto-se les tiene por válido el derecho a dividirse ${ }^{73}$. Por tanto, sería absurdo pensar que existe una obligación territorial, pero lo que sí existe es una obligación al cumplimiento a

\footnotetext{
${ }^{71}$ Se ha sostenido que "las decisiones democráticas directas por regla de la mayoría podrían tener un efecto problemático sobre los derechos de las minorías, resultando en una mayoría que decida en su propio interés, que podría incluir la violación de los derechos de una minoría. Dado que la protección de los derechos civiles y de los derechos de las minorias es un elemento importante de cualquier Estado democrático, podría estar mejor protegido por un sistema de controles y equilibrios que por la legislación [decisión] directa de los ciudadanos". BOCHSLER y SIMON (2015), pp. 206-2017.

72 Aludiendo a los valores del Tratado de Lisboa y al consenso de no ignorar la Constitución y las órdenes del TCE. "EP Plenary session: Constitution, rule of law and fundamental rights in Spain in the light of the events of Catalonia". Opening statement by Frans Timmermans, (European Parliament, 04 October, 2017). Disponible en http://audiovisual.europarl.europa.eu/Assetdetail.aspx?id=bbf14746-0db7-41d8-bb4d-a80100e2c1a8.

73 Como históricamente sucedió con Francia y Argelia, la URSS y Estonia; aunque eran tiempos distintos y los tratados no habían consolidado una gobernanza supranacional con todas las connotaciones, problemas, ventajas y convergencias globales de la actualidad.
} 
lo que manifiestan los tratados, y si en dado caso que se lograra dicha separación las cuestiones pendientes son: ¿Escocia y Cataluña cumplirían con los requisitos que se requiere para ser miembro de la Unión Europea? Y, finalmente, en el caso del Brexit, ante la posible renuncia a la jurisdicción Europea de Derechos $\mathrm{Hu}-$ manos, ¿el poder parlamentario tiene facultades para suprimir derechos humanos y garantía de acceso?

Como vemos, las cuestiones fácticas de referéndums sobre la salida de un Estado de un bloque con uniones políticas, económicas y jurídicas crean tensión en otros Estados y regiones. En el caso de Escocia frente a Inglaterra, y el de Reino Unido frente a la Unión Europea han tenido un impacto sistemático, porque esas decisiones afectan la gobernanza global y generan más dudas que respuestas sobre la viabilidad de la decisión polarizada de un $S I ́$ o un $N O$, ante cuestiones que exigen una deliberación exhaustiva. Por otra parte, también es un hecho notorio que las elites gobernantes deciden crear esferas públicas o preocupaciones no necesariamente para el bien público, sino para favorecer a ciertos grupos de interés político y económico. Aunque es una aspiración legítima de cada grupo plantear la modificación del contrato social, también es cierto que siempre debe existir una pluralidad y apertura al diálogo.

\section{Referéndum de California}

Este referéndum pasó desapercibido en la discusión constitucional debido al volátil momento económico y político que se vivió a finales de 2017. En Estados Unidos, como en algunas federaciones, las prácticas de los referéndums son más activas mediante leyes constitucionales de cada entidad federal. En la elección federal de noviembre de 2017, el estado de California puso a consideración la proposición 64 , sobre el uso recreativo de la marihuana para mayores de 21 años; bajo las condiciones legales y técnicas que imponga el Estado y mediante el pago de impuestos, siempre y cuando se respeten las prioridades federales en la materia.

Este referéndum fue oído con atención en la zona fronteriza MéxicoEstados Unidos, pues toca el tema de legalizar las drogas como mecanismo de combate al narcotráfico. California, con una mayoría del $56 \%$, votó a favor del uso recreativo de la marihuana ${ }^{74}$ y que toma un reclamo social para facilitar nuevas dimensiones del libre desarrollo de la personalidad a través

74 STeinmentz (2017). 
del uso de sustancias nocivas ${ }^{75}$. En tal sentido que el referéndum californiano tiene unos efectos en la despenalización del uso de una sustancia que en su principio estaba prohibida, lo cual no genera en sí una creación de norma constitucional, sino una reforma legislativa trascendente en California. En este caso la despenalización del uso del cannabis es posible afirmar que se trata una extensión de las libertades constitucionales vía referéndum. Con ello se logra la creación de nuevos modelos de vida liberal que busca controlar el uso de una sustancia tóxica. Lo que a su vez resulta interesante es que en el lado fronterizo mexicano no se ha implementado ninguna medida de seguridad ni política pública para enfrentar la licitud de la venta de cannabis en las ciudades fronterizas.

\section{MÉXICO Y LA CONSULTA POPULAR: BARRERA A LA PARTICIPACIÓN CIUDADANA}

En México la situación es muy particular, no se habla del referéndum, sino de consulta popular de acuerdo a lo que establece el artículo 35 constitucional. El mecanismo tiene demasiados requisitos para su aplicación. A cinco años de la reforma, no ha existido ningún procedimiento exitoso de consulta popular, ya que los cuatro procedimientos de consulta popular que se ejercieron entre 2013 y 2014 fueron rechazados por la Suprema Corte de Justicia de la Nación (SCJN) como parte de su papel revisor -en última instancia- de las preguntas de la consulta.

Debemos puntualizar que el artículo 35 fracción VIII de la Constitución reconoce la facultad de convocatoria al Poder Ejecutivo y al Legislativo. De forma marginal, se permite la participación del $2 \%$ de los ciudadanos (del padrón nacional electoral) para proponer la consulta, porcentaje que constituye una barrera inicial. Una segunda barrera es el papel de la Corte para decidir si la pregunta de la consulta es "constitucional". Y una tercera limitación radica en que el resultado será vinculante sólo cuando participe el 40\% de los ciudadanos inscritos en el padrón de electores. También se identifican

\footnotetext{
75 Se trata de una ruptura conceptual sobre el derecho al libre desarrollo de la personalidad, y de cómo en ciertos Estados, los cambios legislativos impulsan la supresión de estas barreras conceptuales sobre el cómo vivir. En asunto que resolvió la Suprema Corte de Justicia de la Nación de México se dijo que la prohibición de consumir cannabis impone modelos y estándares de vida ajenos a los particulares; pues sólo se respeta la identidad de cada sujeto si se le permite actuar en consecuencia a sus propios rasgos, cosmovisiones, concepciones de la vida buena y elementos que, a su juicio, lo definen y singularizan. Vid., 1a Sala, SCJN Amparo en revisión 237/2014.
} 
otras debilidades relacionadas con la falta de claridad que las cuestiones de "trascendencia nacional76".

Por otro lado, en la segunda limitación, de tipo conceptual, la Constitución señala las cuestiones que no se podrán consultar, dejando así temas importantes para el país únicamente a los grupos afines dentro del Congreso y al Poder Ejecutivo, bloqueando de ese modo la participación democrática de las personas. En cuanto al resultado y su efecto vinculante, depende del porcentaje de participación: si participa el 40\% del padrón electoral será vinculante.

Ahora bien, contrario al talante democrático que se obtiene de una lectura sistemática de los artículos 25 y 26 de la Constitución Federal (que le imponen al Estado tomar en cuenta la opinión de los ciudadanos con fines deliberativos), la SCJN, en octubre de 201477 establece que los ciudadanos no estamos legitimados para pedir a la SCJN se pronuncie - previamente- sobre la constitucionalidad de la misma. La justificación de la SCJN en su papel de revisora surge al final y no al principio del proceso. Este rechazo a la participación democrática omite una lectura íntegra de la consulta como programa deliberativo, jurídico, económico y político que se observa en la Constitución mexicana (en sus ar-tículos 1, 25 y 26). A continuación, se presenta un cuadro de las consultas que se han incoado en la SCJN y del sentido de la decisión.

\footnotetext{
76 Ya que se trata de ambigüedades jurídicas. Además, esta postura señala que ni la consulta popular ni la iniciativa de leyes -por parte de los ciudadanos ante los legisladores- son medios efectivos porque "ambas funcionan como una legislación decorativa, puesto que la redacción existe y es posible afirmar que se cuenta con legislación sobre participación, inaplicable”. ALACIO GarCía, Rosa Ynes, (2017), pp. 83-105; el estudio concluye que "El tipo de participación ciudadana que se busca desde la democracia en México se basa en la elección de gobernantes, disociados de las demandas ciudadanas una vez asumido el poder de gobierno, lo que marca las distancias entre la ciudadanía en el poder y frente al poder". Ibídem.

77 Suprema Corte de Justicia de la Nación, "Consulta popular. Los ciudadanos que la soliciten, carecen de legitimación para requerir directamente a la suprema corte de justicia de la nación que se pronuncie sobre la constitucionalidad de la materia de aquélla", Tesis Aislada, Libro 11, octubre 2014, tomo 1.
} 
Tabla 2. Consultas populares en la SCNJ de $\mathrm{México}^{78}$ (elaboración propia)

\begin{tabular}{|l|l|l|}
\hline $\begin{array}{c}\text { Consultas } \\
\text { populares } \\
\text { SCJN }\end{array}$ & \multicolumn{1}{|c|}{ Preguntas planteadas } & \multicolumn{1}{|c|}{ Sentido del fallo } \\
\hline $1 / 2014$ & $\begin{array}{l}\text { ¿Estás de acuerdo o no en que se otorguen } \\
\text { contratos o concesiones a particulares, } \\
\text { nacionales o extranjeros, para la explotación del } \\
\text { petróleo, el gas, la refinación, la petroquímica y } \\
\text { la industria eléctrica? }\end{array}$ & $\begin{array}{l}\text { Se relaciona con los ingresos } \\
\text { del Estado. Es inconstitucional } \\
\text { la materia y la pregunta. }\end{array}$ \\
\hline $2 / 2014$ & $\begin{array}{l}\text { ¿Estás de acuerdo en que se fije un nuevo } \\
\text { salario mínimo que resulte suficiente para que } \\
\text { una familia adquiera los bienes y servicios } \\
\text { requeridos para cubrir sus necesidades } \\
\text { alimentarias o no alimentarias?" }\end{array}$ & $\begin{array}{l}\text { Se relaciona con los ingresos } \\
\text { del Estado. Es inconstitucional } \\
\text { la materia y la pregunta. }\end{array}$ \\
\hline $3 / 2014$ & $\begin{array}{l}\text { ¿Está de acuerdo en que se mantengan las } \\
\text { reformas a los artículos 25, 27 y 28 de la } \\
\text { Constitución en materia energética? }\end{array}$ & $\begin{array}{l}\text { Se relaciona con los ingresos } \\
\text { del Estado. Es inconstitucional } \\
\text { la materia y la pregunta. }\end{array}$ \\
\hline $4 / 2014$ & $\begin{array}{l}\text { ¿Estás de acuerdo en que se modifique la } \\
\text { Constitución para que se eliminen 100 de las 200 } \\
\text { diputaciones federales plurinominales y las } 32 \\
\text { senadurias plurinominales? }\end{array}$ & $\begin{array}{l}\text { Modificaría reglas electorales. } \\
\text { Es inconstitucional la materia } \\
\text { y la pregunta. }\end{array}$ \\
\hline
\end{tabular}

Las cuatro decisiones son notoriamente coincidentes: todas rechazan la consulta popular. Los elementos argumentativos de la mayoría de la SCJN giran en torno a la lectura de las limitaciones del artículo 35 constitucional -fracción VIII- que inhibe de la consulta popular temas específicos. Aunque en las consultas 1, 2 y 3 anteriormente descritas, las justificaciones de la inconstitucionalidad se sustentaron en la construcción (e interpretación) muy amplia del término "ingresos del Estado" que ni la propia Constitución delimita.

En la consulta 2/2014, relativa al salario mínimo, como parte del derecho humano que intenta reorientar la justicia social, el razonamiento del Ministro Cossio Díaz aludió a la necesidad de interpretar la Constitución en bloque y no de forma aislada; mencionó que al rechazar la consulta porque el salario mínimo tiene que ver con los ingresos del Estado ${ }^{79}$ es un equívoco, ya que la definición

\footnotetext{
78 Suprema Corte de Justicia de la Nación: Revisión de Constitucionalidad de la Materia de una Consulta Popular 1/2014, Pleno, 30 de octubre de 2014; Revisión de Constitucionalidad de la Materia de una Consulta Popular 2/2014, Pleno, 29 de octubre de 2014; Revisión de Constitucionalidad de la Materia de una Consulta Popular 3/2014, Pleno, 30 de octubre de 2014; Revisión de Constitucionalidad de la Materia de una Consulta Popular 4/2014, Pleno, 3 de noviembre de 2014.

79 El Ministro Pardo Rebolledo mencionó que afecta los ingresos del Estado indirectamente y que "se dice: es que lo único que se consulta es el salario mínimo como derecho de los trabajadores, y ahi se podría decir: y esto no es ingreso o no es gasto del Estado, yo lo aceptaría; pero si analizamos el salario mínimo en su contexto actual que no solamente está previsto en la Constitución como un derecho indiscutible de los trabajadores, sino que además ha sido utilizado ese concepto como referencia de una gran cantidad de legislación de orden tributaria
} 
de ingresos del Estado no tiene sustento constitucional. Dijo: "me parece que lo que estamos haciendo es interpretar de manera segmentada la Constitución y permitiendo que los mecanismos que la misma establece se entiendan de manera aislada y pulverizada 80 ". Consideramos que la mayoría del pleno de la SCJN no realizó un análisis estructural de los derechos en juego: la consulta popular como derecho colectivo y el derecho a participar en la planeación económica bajo el criterio axiológico de la dignidad humana, la deliberación democrática y para proveer una más justa distribución de la riqueza conforme a lo previsto en los artículos 25 y 26 de la Constitución ${ }^{81}$. Sin embargo, a pesar del bagaje complementario previsto en las disposiciones aludidas, no hubo una referencia a tales preceptos ni se hizo el estudio interdependiente o de la progresividad de los derechos ni del principio pro persona encarnados en el artículo 1 de la Constitución.

La Ministra Sánchez Cordero emite un voto concurrente en el que alude figuras del plebiscito, referéndum y consulta popular en diversos países de Iberoamérica, y del amplio material normativo del derecho internacional de los derechos humanos, vinculante para el Estado mexicano en torno al derecho de participación ciudadana en las decisiones gubernamentales. Así, la Ministra Sánchez Cordero expuso que la consulta popular mexicana incorpora elementos del plebiscito y del referéndum por lo que debe perderse de vista su efectividad en una democracia deliberativa ${ }^{82}$.

Del análisis de los votos y las posiciones formuladas en los procedimientos de consulta que fueron sometidos a consideración de la SCJN, surgieron otras cuestiones que inciden en importantes preguntas de corte constitucional y del

[...] mientras no se haga lo que se ha dado en llamar la 'desindexación' de todos estos elementos respecto del salario minimo, el salario minimo no puede desvincularse de todos estos elementos que lo toman en cuenta". Revisión de Constitucionalidad de la Materia de una Consulta Popular 2/2014, Versión Taquigráfica del Pleno de la SCJN, 29 de octubre de 2014, p. 30.

80 Voto particular que formula el Ministro José Ramón Cossio Díaz. Engrose de la Revisión de Constitucionalidad de la Materia de una Consulta Popular 2/2014, p. 12.

81 El artículo 25 señala: "Corresponde al Estado la rectoría del desarrollo nacional para garantizar [...] que el fomento del crecimiento económico y el empleo y una más justa distribución del ingreso y la riqueza, permita el pleno ejercicio de la libertad y la dignidad de los individuos, grupos y clases sociales, cuya seguridad protege esta Constitución" y el 26 dice con mucha precisión que: "La ley facultará al Ejecutivo para que establezca los procedimientos de participación y consulta popular en el sistema nacional de planeación democrática, y los criterios para la formulación, instrumentación, control y evaluación del plan y los programas de desarrollo".

82 Cfr, Voto Concurrente que formula la Ministra Olga Sánchez Cordero de García Villegas (2014), párrs. 2, 20, 30, 40-42. 
proceso de análisis que se pueda presentar en el futuro ${ }^{83}$. La consulta sobre la reforma energética también se rechazó. El Ministro Aguilar Morales mencionó que se trata de un tema en el que la Constitución establece una restricción por tratarse de ingreso del Estado ${ }^{84}$.

Hasta el momento, se tiene un control constitucional limitativo de la procedencia de las consultas populares; no se han vuelto trascendentes en la vida política y deliberativa de México y mucho menos han contribuido a mejorar el sistema constitucional. Como una diferencia abismal con otros referéndums constitucionales, la sociedad mexicana está marginada de la decisión de su presente y futuro inmediato para ejercer alguna decisión deliberativa.

A cinco años de las reformas constitucionales mexicanas sobre la consulta popular y de la energética la supuesta competitividad alegada por la reforma energética se ha venido abajo bajo un clima de inflación de los combustibles que se vivió a finales de 2017 y que durará todo el año 2017. La interpretación simplista sobre la reforma energética, que en aquel momento realizó la SCJN, no tuvo en cuenta que las decisiones económicas fundamentales deben observar elementos objetivos y no sólo aseveraciones dogmáticas de progreso irreal. ${ }^{85}$ Asimismo, dicha reforma tuvo otras implicaciones geopolíticas, ambientales y financieras que no han sido benéficas para México ${ }^{86}$.

Por otro lado, de los resultados interpretativos de los procedimientos de consulta popular en México se pueden plantear las siguientes interrogantes cons-

83 En relación a los salarios mínimos y su ambigüedad constitucional, el Ministro Juan N. Silva Meza dijo: "Cabe advertir que ni del texto legal ni del constitucional, así como tampoco del proceso de reforma ni de la exposición de motivos, es posible identificar elementos para interpretar el concepto de 'ingresos y gastos' del Estado como objeto vedado de la consulta popular". Voto Concurrente que formula el Ministro Presidente Juan N. Silva Meza (2014), p. 2.

84 Revisión de Constitucionalidad de la Materia de una Consulta Popular 3/2014 (2014), p. 35.

85 En su momento, Cárdenas Gracia advirtió de los riesgos del dominio transnacional y la pérdida de fuentes importantes de ingresos del Estado y la riqueza de la nación y (al crearse un régimen jurídico especial) se anteponen todos los intereses lucrativos de las empresas sobre los intereses nacionales; con la adicional consecuencia nociva del olvido a los derechos fundamentales. CÁrdenAS Gracia, (2014), pp. 124-140.

86 Sobre este punto véase un estudio muy completo que realizan sobre la perspectiva histórica de las reformas constitucionales en el renglón energético y de cómo la reforma es un retroceso del constitucionalismo histórico (nacionalización del petróleo y la industria eléctrica) y pone en una posición muy débil el desarrollo a futuro de México. Cárdenas (2015). Diverso estudio, objetivo y pormenorizado de las iniciativas señala que: " $L a$ apertura del sector energético se sumará a los resultados poco satisfactorios que se han observado en sectores que anteriormente eran controlados por empresas estatales, que fueron abiertos a la participación del sector privado y que actualmente se han convertido en mercados con escasa competencia", MiLler (2014), pp. 3-45. 
titucionales: i) ¿puede el máximo órgano constitucional delimitar los conceptos constitucionales? ii) Si ya se desindexó el salario mínimo de diversos temas fiscales y normas administrativas ${ }^{87}$, ¿sería posible replantear una nueva consulta popular sobre el aumento del salario mínimo?

En cuanto a la cuestión A podemos decir que la delimitación de las normas constitucionales, cuando se trata de conceptos como "ingresos del Estado" deben interpretarse contextualizando todo el iter constitucional que facilite la deliberación económica en torno la planeación económica como asunto de la sociedad y no necesariamente del Estado ${ }^{88}$, y en este caso, estamos ante la omisión de la fuerza normativa de los artículos 25 y 26 de la Constitución. De lo contrario, se corre el riesgo de erosionar la Constitución. En palabras de Néstor Pedro Sagüés "que en definitiva producen una caida en el vigor jurídico [ya que] uno o más tramos del mismo, en efecto, dejarán realmente de aplicarse, a veces incluso con sustitución del contenido constitucional, por más que el operador simule que los está haciendo funcionar a pleno ${ }^{89}$ ". El riesgo advertido es claro, las interpretaciones manipulativas que le dan otro sentido a las normas constitucionales no tienen justificación racional ni teleológica en un sistema constitucional.

Por otro lado, la consulta es parte del derecho político de los ciudadanos a inmiscuirse en la vida político-económica de su Estado y participar en las decisiones trascendentales que, de manera directa, le podrían afectar. En estas condiciones, y ante la barrera que puso la SCJN para inhibir la consulta, el Poder Ejecutivo

87 El Diario Oficial de la Federación del 27 de enero de 2017 establece la reforma al artículo 26 de la Constitución y dice: "El organismo calculará en los términos que señale la ley, el valor de la Unidad de Medida y Actualización que será utilizada como unidad de cuenta, indice, base, medida o referencia para determinar la cuantía del pago de las obligaciones y supuestos previstos en las leyes federales, de las entidades federativas y del Distrito Federal, asi como en las disposiciones juridicas que emanen de todas las anteriores".

88 Consideramos, debido a cierta vaguedad de su contenido, la interpretación de la Constitución mexicana de participación se aparta de los nuevos modelos constitucionales que favorecen la participación. Por ejemplo, la Constitución de Bolivia en su Título VI artículos 241 y 242 reconoce los procesos de participación y control social de las políticas, los planes económicos. En el artículo 316 dispone que "La Función del Estado en la Economía consiste en 1. Conducir el proceso de planificación económica y social, con participación y consulta ciudadana".

89 Esto es parte del acoso que sufre la Constitución de acuerdo a los procesos de Desconstitucionalización, que prevalece "cuando una regla constitucional no es formalmente cambiada, pero sí resulta desvirtuada, pervertida, bloqueada o desnaturalizada, especialmente por prácticas, costumbres o interpretaciones mutativistas, generalmente manipulativas de la Constitución”. SAGỨs, Néstor Pedro, La Constitución bajo tensión, Instituto de Estudios Constitucionales de Querétaro, p. 106. 
aprobó la reforma energética el 20 de diciembre de $2013^{90}$. A finales del año 2017 y en todo el 2017, lo que tenemos es dependencia energética, desabasto de combustibles, inflación de otros productos y volatilidad económica en todos los sentidos.

En suma, los resultados de las consultas populares en México son inexistentes y la consultada adolece de talante democrático. Las elites de la democracia antideliberativa no han dejado crear un mecanismo donde la SCJN tenga una visión más amplia de la consulta como derecho humano conectado con la democracia, la deliberación, la justa distribución de la riqueza y la exigibilidad de las cláusulas económicas de la Constitución.

\section{LOS PROBLEMAS CONSTITUCIONALES DE LOS REFERÉNDUMS: MUCHA POLÍTICA Y POCA DELIBERACIÓN}

De las experiencias del referéndum en Cataluña, Reino Unido, Escocia, y del modelo mexicano - de consulta popular- se pueden obtener variables sobre la efectividad, los alcances y los problemas constitucionales que no se analizan antes sino después de su ejercicio. De inicio, podemos afirmar que los modelos escocés, británico y californiano tienen reglas claras de su ejercicio y efecto vinculante. No así el mexicano, pues la intervención de los jueces constitucionales fue un criterio definitivo para su ejercicio. En el caso catalán, se apartó de toda regla constitucional y de facto fue más un acto político al margen constitucional.

Aunque es deseable que el referéndum sea un instrumento que facilite el consenso, o, como señala Pedro de Vega, que sea el mecanismo más idóneo para salvar el concepto de legitimidad, asentado en la realización de los principios de la verdad y la justicia ${ }^{91}$, algunos referéndums surgen como intentos o herramientas desesperadas de los gobiernos cuya legitimidad se desvanece ${ }^{92}$. Se adaptan como fórmulas mediante las que se quiere fortalecer la legitimidad con preguntas que tienen apoyo popular, que bien pueden tener una solución legislativa en otros

\footnotetext{
90 Con las modificaciones constitucionales de fondo a tres artículos de la Constitución. Véase el Diario Oficial de la Federación, Decreto, 20 de diciembre de 2013.

91 Pedro de Vega, op. cit., p. 24.

92 O, según Auer, que tienden a compensar la legitimación de legislaturas y estructuras políticas. AuER, op. cit., p. 401.
} 
momentos ${ }^{93}$. También pueden ser intentos de los partidos y grupos políticos con una agenda radical para hacer valer sus posiciones frente al conglomerado social, sin que se lleguen a soluciones meditadas en la esfera pública (como el caso del Brexit y Cataluña).

Es claro que, en los diversos contextos políticos analizados, el fondo de los planteamientos tiene que ver con conflictos que se generan entre un grupo minoritario y el gobierno, entre partidos o como una salida a problemas técnicos de gobernabilidad (como el gasto público entre el gobierno central España y Cataluña, las aportaciones de Inglaterra a la Unión Europea, la licitud de la marihuana en California o la viabilidad de la reforma energética en México) mediante la decisión de las mayorías. A veces se trata de un intercambio de favores políticos que los grupos elitistas provocan entre sí; y en este sentido falla ${ }^{94}$ porque, a diferencia del proceso legislativo en donde se escuchan posiciones de las minorías y se incorporan los disensos, en los referéndums se emite una decisión excluyente y con un resultado negativo para la minoría cuya voz ya no será oída. Desde la experiencia comparada, se ha dicho que el referéndum no favorece la deliberación sino el cierre constitucional ${ }^{95}$.

Como se ha dicho, el referéndum es un mecanismo de participación para la toma de decisiones, aunque no necesariamente deliberativo. Otro elemento de los casos aludidos es la necesidad de intervención de las Cortes Constitucionales (México, Reino Unido y España), es decir, a raíz del referéndum se busca una solución desde la justicia constitucional.

El referéndum de Escocia fue el ejercicio que menos turbulencia tuvo. Se realizó el ejercicio democrático de manera exitosa, apegado al marco constitucional británico, con respeto a la soberanía parlamentaria y popular, con las campañas necesarias para comprender el alcance de la decisión constitucional y el respeto al resultado del referéndum. Es por ello que no se puede comparar con el pro-

\footnotetext{
93 Este fue el caso de la consulta popular 4/2014 impulsada por los grupos parlamentarios del PRI (Partido Revolucionario Institucional) y la 2/2014 del PAN (Partido Acción Nacional). El PRI ha tenido oportunidades -en todo momento. de reducir el número de integrantes de los diputados plurinominales a lo largo de su hegemonía - de 70 años- como partido mayoritario en México (hasta 1997) y como una de las tres fuerzas dominantes en los últimos 20 años; y -a pesar de ser un hecho notorio- no lo había propuesto. El Partido Acción Nacional pudo haber impulsado en los sexenios de 2000-2006 y 2006-2012 una política económica a favor del salario de los trabajadores, pues tuvo bajo su mando la competencia exclusiva del Poder Ejecutivo de fijar los salarios por 12 años y no lo hizo.

$94 \mathrm{Al}$ respecto véase el estudio planteado por SHAun y Todd (2001), pp. 109 y ss.

95 Así Soto (2017), pp. 291-306.
} 
ceso catalán, pues objetivamente no hay ninguna relación de normas, procesos o legitimidad.

En un panorama amplio, el Brexit y Cataluña presentan mucha turbulencia para implementar la decisión, eso se debe a que no se analizó debidamente el alcance del resultado ni hubo un diálogo entre todas las partes implicadas. La decisión de retirarse de una unión que lleva más de medio siglo (y que fue producto de la reconstrucción de Europa en la posguerra) puede darse con una votación, pues se trata de cuestiones no decidibles mediante el voto. Ello tiene que ver con la naturaleza de la decisión constitucional o de la forma del reconocimiento de la vinculación 96 .

Por otro lado, la forma de Estado no garantiza el éxito del referéndum, $v$. gr., a pesar de la madurez de la democracia parlamentaria británica, su ejercicio estuvo sustentado en una campaña llena de falacias sobre lo positivo de la salida de Europa; sin medir las consecuencias reales del resultado ${ }^{97}$ y que las negociaciones con los restantes miembros de la Unión no serían fáciles. Esta desventaja del referéndum también se ha destacado en otros ejercicios en la etapa de implementación del resultado. ${ }^{98}$ Fue la puerta para el descontento social y el ulterior proceso constituyente. Ante su falibilidad, el referéndum no es la panacea democrática y debe ser visto como un mecanismo complementario en el que se tienen que tomar en cuenta todos los sectores bajo el marco del programa político de la Constitución. $\mathrm{Y}$ en temas sobre las relaciones internacionales, no se puede evitar sopesar esa realidad internacional, para conocer las ventajas y desventajas. En este aspecto, lo recomendable para orientar y favorecer la deliberación es acudir a sectores especializados que deben tomarse en cuenta y, sobre todo, para racionalizar la decisión de la autoridad.

\footnotetext{
96 Esto puede explicar el problema de la implementación cuando la decisión es en torno a la integración o desintegración del Estado. Después de analizar diversos países en Europa esta es la conclusión de UlLERI (1996).

97 John Major, ex-primer ministro, dijo: "It is time for the minority of 'ultra-Brexiteers' - those who believe in a complete break from Europe - to stop shouting down anyone with an opposing view. It is not only unattractive but profoundly undemocratic and totally un-British". [...] It was dishonest and wrong to promise the British people an easy, favourable deal with the EU, wrong to promise swift new trade deals. Disponible en: The Guardian (2017): "John Major attacks 'ultra-Brexiteers' as undemocratic and un-British" https://www. theguardian.com/politics/2017/mar/19/john-major-attacks-ultra-brexiteers-undemocratic-un-britishtheresa-may-eu-brexit.

98 En el caso del referéndum de 2003 en Bolivia, la decisión -al provocar la caída del Poder Ejecutivo y la desconfianza en el Legislativo. Sobre este tema vid., Arrarás y Deheza (2005).
} 
Según Olivetti

"Es de hecho sabido que característica esencial de las democracias pluralistas es la riqueza y la variedad de las vías y de los medios mediante los que la sociedad y los grupos que la componen pueden expresar sus opiniones y hacer valer sus intereses: partidos politicos, asociaciones, sindicatos, los viejos y nuevos medios de comunicación, que juegan un papel esencial [...] sino que puede ser uno de los instrumentos más útiles para controlar las decisiones de las autoridades gobernantes y para completar e integrar el funcionamiento de las instituciones representativas ${ }^{99 "}$.

De acuerdo a los elementos tradicionales de la lucha para modular las decisiones del poder, es claro que la política se impone al derecho constitucional. En su mayoría, los poderes políticos tratan de ganar adeptos a sus causas mediante la popularización de las decisiones, aunque éstas no siempre son adecuadas, o al menos viables. En este sentido, la deliberación democrática implica un compromiso de proteger los derechos de las minorías, a quienes el resultado del referéndum no les favorecerá. Este diálogo siempre debe orientarse en la gramática constitucional y de los derechos humanos en la búsqueda de un significado objetivo y sistemático del resultado deliberativo.

\section{CONCLUSIÓN}

Las conclusiones que se extraen de los ejercicios de los referéndums constitucionales estudiados son cualitativas. En primer lugar, podemos afirmar que tanto Escocia, como Reino Unido y California tienen una legislación especial, y con ello se garantizan reglas claras. En el caso de Cataluña (España) y México las reglas constitucionales son claras, pero el contexto político impide un resultado objetivo.

Otra cualidad de estos referéndums es que el planteamiento de la pregunta, o cuestión constitucional, puede ser problemática. Y de ello depende el éxito de su implementación. De los casos analizados, sólo California y Escocia implementaron la decisión sin mayores problemas. Los resultados del Brexit y el referéndum catalán están en suspenso; lo único palpable es que han creado más tensiones políticas de las que intentaban resolver. En ambos casos, se perdieron de vista los elementos deliberativos para plantear los referéndums. En buena medida las preguntas que se formulan merecen un análisis amplio desde la teleología constitucional y su-

99 Olivetti (2007), pp. 147-175. 
pranacional. A su vez, se debe pensar en el diseño de un plan de trabajo a corto o mediano plazo para construir el resultado del referéndum.

También se advierte que el proceso deliberativo depende del diseño constitucional previamente dispuesto: de la plataforma jurídica, los actores, y la claridad de los efectos (vinculantes o no). En el sistema constitucional británico el resultado del referéndum (tanto de Escocia como el Brexit) tiene posibilidades reales de llevarse a cabo. Aunque ello implica lidiar con la tensión constitucional interna y -en el caso del Brexit- con la presión y desventajas para negociar la salida de la Comunidad Europea. ${ }^{100}$ A diferencia de la consulta popular en México que, a pesar de su diseño constitucional con reglas claras, su ejercicio depende de los filtros y barreras constitucionales que el propio legislador constitucional estableció. En el caso del referéndum de California, en virtud de la existencia de otros estados con la implementación del consumo del cannabis, lo que logró el referéndum fue regular una situación que ya existía como práctica reiterada.

Por otro lado, de los ejercicios analizados, podemos concluir que una vez que surge el resultado pueden presentarse problemas para su implementación. Ello se debe a que el tipo de decisión no puede partir de una bipolaridad (tan tajante como el Sí o NO) que rompa el esquema de las relaciones internas, regionales e internacionales de los Estados (como ocurre con el Brexit y Cataluña) y que no respete la decisión de los grupos minoritarios. Así, lo que queda al descubierto es que el referéndum puede esconder un cierre del grupo político dominante que excluye la voz de las minorías. Bajo estas pautas, consideramos que las reglas operativas y las materias del referéndum deben ser planteadas con mucha precisión para evitar equívocos y crisis constitucionales.

Una parte no vista de los referéndums es la intervención de diversos actores: medios nacionales, internacionales, empresarios, grupos de presión, universidades y minorías. Cada uno con sus intereses propios y muy divergentes. Es claro que la sociedad quiere ser oída por el poder político; quiere ser tomada en cuenta en las decisiones, pero hace falta vertebrar estas participaciones en procesos abiertos y de consenso. El gran peligro que corren los referéndums es que pierdan su enfoque inclusivo y se conviertan en una herramienta demagógica, con resultados inesperados en contra de los propios actores sociales. En el caso de Cataluña,

\footnotetext{
100 Hasta el 12 de octubre de 2017, las negociaciones entre el gobierno británico y Europa se hallaban en punto muerto. Incluso se habla de un segundo referéndum debido a un cambio de postura de la mayoría de británicos para dar reversa al Brexit. Véase "Brexit talks in 'disturbing deadlock' over divorce bill, says EU negotiator" (The Guardian, 2017). https://www.theguardian.com/politics/2017/oct/12/brexit-talks-atdisturbing-deadlock-over-divorce-bill-says-eu-negotiator.
} 
por ejemplo, no se valoró el impacto económico y la salida de inversión a través del cambio de sede de Bancos y empresas ${ }^{101}$. Por estas razones, un referéndum constitucional obliga a crear coordenadas de la deliberación pública que visualicen todos los posibles efectos del resultado.

Orientar a los referéndums bajo el prisma constitucional es un trabajo pendiente para los constitucionalistas y los estudiosos de la ciencia política. En suma, el referéndum no agota los mecanismos de participación ciudadana, que en diversos casos se contamina por los intereses y oportunismos políticos del momento. Los referéndums juegan un papel protagónico como herramienta en clave deliberativa para la construcción de la participación social. Es por ello que, a toda costa, debemos evitar que el referéndum opaque la deliberación y el diálogo político al que están obligados los poderes públicos; todo lo contrario, debemos auspiciar mecanismos de participación ciudadana incluyentes, racionales y deliberativos, antes de que la irresponsabilidad de líderes políticos aumenten la ingobernabilidad y pulvericen la democracia.

\section{BiBLIOGRAFÍA CITADA}

Aguilar López, Juan F. (2017): “Cuestión Catalana y Crisis Constitucional”, en Teoría y Realidad Constitucional, pp. 273-308.

Alacio García, Rosa Ynes. (2017): “La reforma político-electoral 2013-2014. Una participación ciudadana a medio camino", en Revista Mexicana de Opinión Pública (Vol. 20), pp. 83-105.

Antonsich, Marco. (2010): "Mapping the Referendum on the Swiss minaret ban”, en Revista Political Geography, vol. 29 (2), pp. 57-62.

Arrarás, Astrid y Deheza, Grace. (2005): "Referéndum del gas en Bolivia 2004: mucho más que un referéndum”, Revista de Ciencia Política. (Vol. 25 No 2), pp. 161-172.

Auer, Andreas. (2017): “The people have spoken: abide? A critical view of the EU's dramatic referendum (in)experience" (Editorial), European Constitutional Law Review, (vol. 12 issue 3), pp. 397-408.

Bortoli, Gilbert. (1965): Sociología del Referendum en Francia. L.G.D.J. París. BochSLER, Daniel; Hug, Simon. (2015): "How minorities fare under referendums: A cross-national study", Electoral Studies, (Volume 38), pp. 206-2017.

101 Cada vez se suman más empresas nacionales y globales. Véase "Estas son todas las empresas que se van de Cataluña”. (El País 2017). 
Bowler, Shaun; Donovan, Todd. (2001). "Popular Control of Referendum Agendas: Implications for Democratic Outcomes and Minority Rights", en Mendelson Matthew y Parkin Andrew, Referendum Democracy. Citizens, Elites and Deliberation in Referendum Campaigns, Palgrave, pp. 109 y ss.

Breuer, Anita (2009): The Use of Government-initiated Referendums in Latin America. Towards a Theory of Referendum Causes. 29, pp. 23-55.

Butler, David; Ranney, Austin (eds.), (1994). "Referéndums around the world. The growing use of direct democracy", AEI Press.

Cagiao y Conde, Jorge. (2015). "La crisis del modelo de Estado en España y la reforma federal”, en revista electrónica Cahiers de civilisation espagnole contemporain, disponible en https://ccec.revues.org/5964\#entries.

Cárdenas Gracia, Jaime. (2014): Crítica a la Reforma Energética de 2013, (IIJUNAM, México).

Cárdenas Gracia, Jaime. (2017). "Informe sobre el Referéndum Boliviano de 2017", en Boletín Mexicano de Derecho Comparado, (Nueva Serie Año XLX Núm. 148), pp. 81-112.

Cárdenas Gracia, Jaime. (coord.) (2015). Reforma Energética. Análisis y consecuencias, (México, UNAM-Tirant lo Blanch).

Casanova Álvarez, Francisco; Corona Armenta, Gabriel (coords.) (2013).

"Democracia Interna y tendencias oligárquicas de los partidos políticos en México: PAN, PRI y PRD”, Gernika.

Castellá Andreu, José María (2014): "La secesión catalana. Entre la política y el derecho", en Anuario de la Facultad de Derecho, (No 7), pp. 229-240. (España, Universidad de Alcalá).

Clavellina Miller, José Luis (2014): "Reforma Energética. ¿Era realmente necesaria?”, Economía Informa, (Vol. 385), March-April, pp. 3-45.

Corona Armenta, Gabriel (coord.), (2014): "Democracia interna y tendencias oligárquicas de los partidos políticos en México: Partido Verde Ecologista, Partido del Trabajo, Movimiento Ciudadano y Nueva Alianza”, Gernika.

Corte Nacional Electoral de Bolivia (2007)": "Resultados Finales. Referéndum Constituyente". Disponible en https://www.vicepresidencia.gob.bo/IMG/pdf/ referendum_constituyente.pdf.

Davies, Bleddyn (2015): "Popular Participation and Legitimacy in Constitutional Change: Finding the Sovereign”, Liverpool Law Review, November. Volume 36, Issue 3, pp. 277-297. 
De los Santos Olivo, Isidro (2010): "Plebiscito y Referéndum. Concepciones entre Democracia Directa y Representativa. Puntual Tratamiento entre el Constitucionalismo Estatal y Comparado", en César Astudillo y Manlio Fabio Casarín León, Derecho constitucional estatal. Memoria del V Congreso Nacional de Derecho Constitucional de los Estados, UNAM.

De Vega García, Pedro (1996): "En torno a la crisis de representación y de legitimidad en la democracia actual”, en Soberanes Fernández, José Luis, Valadés, Diego, Concha, Hugo A., (eds.), La Reforma del Estado. Estudios Comparados, (México UNAM).

De Vega García, Pedro (2012): (Conferencia) "La reforma del Estado y de la Administración española” disponible en https://vimeo.com/56802960, fecha de consulta: 10 de marzo de 2017.

Ferreres Comella, Víctor (2017): "Cataluña y el derecho a decidir", en Teoría y Realidad Constitucional (núm. 37), pp. 461-475.

Gordon, M. (2017): "Brexit: A challenge for the UK constitution, of the UK constitution?”, European Constitutional Law Review, (vol. 12 issue 3), pp. 409-444.

Gaudreault-Desbiens, Jean-François (2017): "Algunos de los desafíos legales y políticos que debe afrontar el movimiento de independencia de Quebec", en Teoría y realidad constitucional núm. 37.

Hetherington, Marc J.; Rudolph, Thomas J., (2015): Why Washington Won't Work: Polarization, Political Trust, and the Governing Crisis, (The University of Chicago Press, Chicago).

Lars P., Feld; MatsusaKa, John G. (2003): "Budget referendums and government spending: evidence from Swiss cantons", Journal of Public Economics, (vol. 87. Issue 12), pp. 2703-2724.

LEDUC, Lawrence (2015): "Referendums and deliberative democracy", Electoral Studies, (Volume 38), pp. 139-148.

Mendilow, Jonathan (ed.) (2012): Money, Corruption and Political Competition in Established and Emerging Democracies, Lexington Books, London.

Marcou, Gérard. (2011): "Región y regionalización en los Estados unitarios de Europa” en Valadés, Diego et al. (coords. constituc.), (2011), Ideas constitucionales en el siglo XX, Siglo XXI Editores, (México, UNAM).

Olivetti, Marco. (2007). "Los Referéndums en serio: la experiencia italiana". Revista Jurídica Universidad Autónoma de Madrid, Núm. 15, pp. 147-175.

Oliver Araujo, Joan. (1986): El referéndum en el derecho constitucional español, en Cuadernos de la Facultad de Derecho, Palma Mallorca. 
PAGE, Alan (2017): "El Referéndum de Independencia Escocés", Teoría y Realidad Constitucional (núm. 37), pp. 437-448.

Pericleous, Chrysostomous: Cyprus Referendum: A Divided Island and the Challenge of the Annan Plan, (e-book. Taurus, London, 2009).

PirIs, Jean-Claude (2017): "La Unión Europea, Cataluña y Escocia (Cuestiones jurídicas sobre las recientes secesionista en los Estados Miembros de la UE)”. Revista Teoría y Realidad Constitucional, (núm. 37), pp. 101-134.

Proceso Independista Catalán, "Podemos apoyar un referéndum de independencia en Cataluña”. Disponible en https://mundo.sputniknews.com/ espana/201709191063553620-espana-cataluna-independencia-siqueespot/. Consultada: 19 de septiembre de 2017.

ReICHTERT, Fabia (2013): You Vote What you Read? News coverage before the two Irish Referendums on the Lisbon Treaty, ((e-book) Anchor, Hamburg).

SAGÜÉS, Néstor Pedro (2017): La Constitución bajo tensión, (Instituto de Estudios Constitucionales de Querétaro, México).

Serna de la Garza, José María (2011): "El Estado Federal" en Valadés, Diego et al. (coords.), Ideas constitucionales en el Siglo XX, Siglo XXI Editores, (México, UNAM).

Scherer García, Julio (2011): Historias de Muerte y Corrupción. Calderón, Mouriño, Zambada, El Chapo y la Reina del Pacifico (Grijalbo Mondadori, México). Schuck, Andreas R.T.; De Vresse, Claes H. (2015): "Public support for referendums in Europe: A cross-national comparison in 21 countries", en Revista Electoral Studies, (Volume 38), pp. 149-158.

Soto Barrientos, Francisco (2013): "El Referéndum en Latinoamérica: un análisis desde el derecho comparado", en Revista Boletín Mexicano de Derecho Comparado, (vol. XLVI, núm. 136), pp. 317-346 (México, UNAM).

Soto BARrientos, Francisco (2017): "La regulación del referéndum de especial trascendencia en perspectiva comparada y su eventual reconocimiento en la Constitución chilena”, en Revista Estudios Constitucionales, núm. 14, pp. 291306.

Tierney, Stephen (2014): Constitutional Referendums. The Theory and Practice of Republican Deliberation, Inglaterra: Oxford University Press.

ReIdy, Theresa y SuITER, Jane. (2015): “Do rules matter? Categorizing the regulation of referendum campaigns", en Revista Electoral Studies, Volume 38, June, pp. 159-169. 
Trench, Allan (2010): “The Evolution of Devolution”, en Robert Hazell (ed.), Constitutional Futures Revisited. Britain's Constitution to 2010, Palgrave MacMillan. VÁzQuez Alfaro, José Luis (2001): "El referéndum del quinquenio en Francia", Cuestiones Constitucionales, (núm. 5), pp. 305-315 (México, Universidad Nacional Autónoma de México).

VInCENZO, Ulleri (1996): The Referendum Experience in Europe, Galleger, Michael y Uleri Pier Vincenzo (MacMillan Press Ltd., London).

Welp, Yanina, (2009): "España frente el Referéndum Europeo: o de la Democracia y sus Debilidades", Revista Confines de Relaciones Internacionales y Ciencia Politica. Disponible en:<http://www.redalyc.org/articulo.oa?id=63311911003> issn 1870-3569.

Yadav, Vineeta (2011): Political Parties, Business Groups, and Corruption in Developing Countries (Oxford University Press), UK.

\section{JURISPRUDENCIA CITADA}

High Court of Justice Royal Court de Inglaterra (2017): The Queen on the application and The Secretary of State for Exiting the European Union. CO/3809/2017 \& CO/3281/2017 (3 de noviembre de 2017).

Suprema Corte de Justicia de la Nación (México), Revisión de Constitucionalidad de la Materia de una Consulta Popular 1/2014, derivada de la solicitud formulada por Martí Batres Guadarrama, representante común de diversos ciudadanos. Versión Taquigráfica del Pleno, 30 de octubre de 2014.

Suprema Corte de Justicia de la Nación (México), Revisión de Constitucionalidad de la Materia de una Consulta Popular 2/2014, derivada de la solicitud formulada por Gustavo Enrique Madero Muñoz. Versión Taquigráfica del Pleno, 29 de octubre de 2014.

Suprema Corte de Justicia de la Nación (México), Revisión de Constitucionalidad de la Materia de una Consulta Popular 2/2014, Versión Taquigráfica del Pleno, 29 de octubre de 2014.

Pleno de la Suprema Corte de Justicia de la Nación (México), Revisión de Constitucionalidad de la Materia de una Consulta Popular 3/2014, derivada de la solicitud formulada por José de Jesús Zambrano Grijalva, representante común de diversos ciudadanos. Versión Taquigráfica del Pleno 30 de octubre de 2014.

Pleno de la Suprema Corte de Justicia de la Nación (México), Revisión de Constitucionalidad de la Materia de una Consulta Popular 4/2014, derivada de la 
solicitud formulada por César Octavio Camacho Quiroz y diversos ciudadanos. Versión Taquigráfica del Pleno, 3 de noviembre de 2014.

Suprema Corte de Justicia de la Nación (México), Voto Concurrente que formula la Ministra Olga Sánchez Cordero de García Villegas en el Engrose de la revisión de la constitucionalidad de la materia de la consulta popular 1/2014.

Suprema Corte de Justicia de la Nación (México), Voto concurrente que formula el Ministro Presidente Juan N. Silva Meza en la revisión de constitucionalidad de la materia de la consulta popular 1/2014.

Pleno de la Suprema Corte de Justicia de la Nación (México), Voto Particular que formula el Ministro José Ramón Cossio Díaz en el Engrose de la Revisión de Constitucionalidad de la Materia de una Consulta Popular 2/2014.

Suprema Corte de Justicia de la Nación (México), "Consulta popular. Los ciudadanos que la soliciten, carecen de legitimación para requerir directamente a la Suprema Corte de Justicia de la Nación que se pronuncie sobre la constitucionalidad de la materia de aquélla”. Tesis Aislada, Libro 11, octubre 2014. Tomo 1.

Suprema Corte de Justicia de la Nación (México), Primera Sala, Amparo en revisión 237/2014.

Suprema Corte de Justicia de la Nación, Primera Sala: Amparo en Revisión 631/2012 (Sentencia aclaratoria 7 de agosto de 2013) y Segunda Sala: Amparos en revisión: 198/2015, 241//2015, 270/2015, 410/2015, 498/2015, 499/2015 y 500/2015. (Resolución de 4 de noviembre de 2015).

Suprema Corte de Justicia del Reino Unido $R$ (on the application of Miller and another) (Respondents) $v$ Secretary of State for Exiting the European Union (Appellant) [2017] UKSC5, 24 de enero de 2017.

Suprema Corte de Justicia del Reino Unido, (2017) R (on the application of Miller and another) (Respondents) v Secretary of State for Exiting the European Union (Appellant), Press Summary, 24 January 2017.

Tribunal Constitucional de España (TCE), Sentencia 42/2014, publicada en el Boletín Oficial del Estado en 10 de abril de 2014.

Tribunal Constitucional de España (TCE), Sentencia 103/2008, publicada en el Boletín Oficial del Estado en 10 de octubre de 2008.

\section{NORMAS JURÍDICAS CITADAS}

Constitución de España de 1978. Última reforma, septiembre 27 de 2011. 
Constitución Mexicana de 1917, Cámara de Diputados del H. Congreso de la Unión. Última reforma de 15 de septiembre de 2017.

Constitución del Estado de California de 1879. Assembly of California. Última reforma de 2017. Reino Unido European Union Referendum Act 2015. Her Majesty's Stationery Office, 17 de diciembre de 2015.

Reino Unido, The Scottish Independence Referendum Act, Her Majesty's Stationery Office, 17 de diciembre 2013.

\section{OTRAS FUENTES DE INFORMACIÓN CITADAS}

Arístegui Noticias (2017): Brexit comienza a hundir el peso. Disponible en http:// aristeguinoticias.com/2406/mexico/brexit-hunde-al-peso-cae-7-21-y-videgaray-llama-a-reunion-urgente/.

Ballotpedia (2017): “Marijuana on the Ballot”. Disponible en: https://ballotpedia. org/Marijuana_on_the_ballot

Charlie Hebdo (2017): No 1316, Edition du 11 Oct., Paris.

Council of Europe (2005): "Referendums: towards good practices in Europe". Doc. 10498, report of the Political Affairs Committe. Disponible en http://assembly. coe.int/nw/xml/XRef/Xref-XML2HTML-en.asp?fileid=17329\&lang=EN.

Estadística de Irlanda: https://www.electionsireland.org/results/referendum/ refdetail.cfm?ref=201129R.

House of Commons (2017): European Union (Notification of Withdrawal) Bill, (vol. 641). Disponible en https://hansard.parliament.uk/Commons/2017-02-08/debates/B9545C0C-B593-43E4-A12E-2AD5D47DEFE4/EuropeanUnion(NotificationOfWithdrawal)Bill\#division-7082.

House of Commons (2017): Tim Robinson (comp.). Brexit reading list: legal and constitutional issues, disponible en http://researchbriefings.files.parliament.uk/ documents/CBP-7702/CBP-7702.pdf.

El País, (2017): "Rajoy activa el 155 con apoyo del PSOE y accede a reformar la Constitución”. Disponible en https:/politica.elpais.com/politica/2017/10/11/ actualidad/1507705563_381296.html.

El País, (2017): "Estas son todas las empresas que se van de Cataluña”, https:// elpais.com/economia/2017/10/09/actualidad/1507570625_950581.html.

Martin Scheinin, Blog IACL-AIDC, (2017): "Catalans May Not Have the Right to Unilateral Secession - But They Do Possess the Right to Present Such a Claim", disponible en https://iacl-aidc-blog.org/2017/10/09/catalans-may- 
not-have-the-right-to-unilateral-secession-but-they-do-possess-the-right-topresent-such-a-claim/

Parlamento Europeo, (European Parliament, 04 October, 2017): "EP Plenary session: Constitution, rule of law and fundamental rights in Spain in the light of the events of Catalonia". Opening statement by Frans Timmermans. Disponible en http://audiovisual.europarl.europa.eu/Assetdetail.aspx?id=bbf147460db7-41d8-bb4d-a80100e2c1a8.

Steinmentz, Katy (2017): "What to Know About Marijuana Legalization in California”, Time U.S. (2017). Disponible en http://time.com/4565438/ california-marijuana-faq-rules.

The Irish Independent (2017): Geoffrey Robertson, "If you think the High Court is interfering in democracy, then you don't understand how Britain works", http://www.independent.co.uk/voices/high-court-ruling-article-50-brexit-eureferendum-parliamentary-vote-leaving-european-union-british-a7395966. html, nota del 3 de noviembre de 2017, último acceso: 21 de abril de 2017.

The Guardian (2017): “The post-Brexit pound - how sterling's fall affects you and the UK economy”. Disponible en https://www.theguardian.com/business/2017/aug/19/the-post-brexit-pound-how-sterlings-fall-affects-the-ukeconomy.

The Guardian (2017): "Pound slumps to 31-year low following Brexit vote". Disponible en https://www.theguardian.com/business/2017/jun/23/britishpound-given-boost-by-projected-remain-win-in-eu-referendum.

The Telegraph (2017): “UK 'obliged' to accept judgments of European courts, official document from ministers ahead of EU referendum reveals". Disponible en http://www.telegraph.co.uk/news/2017/04/14/uk-obliged-judgments-ofeuropean-courts-official-document-from-m/. 